\title{
Transformation in Property and Copyright
}

Christopher M. Newman

Follow this and additional works at: https://digitalcommons.law.villanova.edu/vlr

Part of the Intellectual Property Law Commons

\section{Recommended Citation}

Christopher M. Newman, Transformation in Property and Copyright, 56 Vill. L. Rev. 251 (2011).

Available at: https://digitalcommons.law.villanova.edu/vlr/vol56/iss2/3

This Article is brought to you for free and open access by Villanova University Charles Widger School of Law Digital Repository. It has been accepted for inclusion in Villanova Law Review by an authorized editor of Villanova University Charles Widger School of Law Digital Repository. 


\title{
TRANSFORMATION IN PROPERTY AND COPYRIGHT
}

\author{
Christopher M. NeWMaN*
}

\section{INTRODUCTION}

\section{A. The Transformation Problem in Copyright}

$\mathrm{C}$ OPYRIGHT law grants ownership rights in "works of authorship,"1 Aand copyright disputes frequently require us to distinguish between two different ways in which a work of authorship may be "transformed." On one side of the line are changes whose end result is termed a "derivative work," and which are therefore subject to the exclusive rights of the author. ${ }^{2}$ On the other side are changes resulting in a "transformative fair use," which fall outside those rights. ${ }^{3}$

It can be very difficult to distinguish between the two with confidence, because the boundary between them is determined by the interplay between two open-ended doctrines. The first is "substantial similarity," which describes the relationship two works must have if one is to be regarded as constituting either a "reproduction" or a derivative work of the other. ${ }^{4}$ Though one would expect the category of reproductions to be much narrower than that of derivative works, in practice the two have largely merged, and are governed by the same standard of substantial similarity. ${ }^{5}$ The meaning of reproduction has thus expanded to include both

* I wish to thank all of the following for advice, support, and/or constructive feedback: Eric Claeys, Adam Mossoff, Henry Butler, Scott Kieff, Larry Ribstein, David Haddock, Michael Abramowicz, Bruce Kobayashi, Bruce Johnsen, Lloyd Cohen, T.J. Chiang, David Schleicher, Rachelle Holmes, Nelson Lund, Jeremy Rabkin, Rebecca Tushnet, Pam Samuelson, Madhavi Sunder, Brian Holland, Kevin Collins, Matt Sag, Henry Smith, Neil Netanel, Julie Cohen, Bruce Frier, Lawrence Saporta, Peter Lee, and all the participants in workshops at the Virginia Junior Faculty Forum at Richmond University School of Law, the 2010 Intellectual Property Scholars Conference, and the Levy Workshop at George Mason University School of Law.

1. See 17 U.S.C. $\$ 102$ (2006) ("Copyright protection subsists, in accordance with this title, in original works of authorship .....).

2. See 17 U.S.C. $\$ 101$ (2006) (defining "derivative work" to include "any . . . form in which a work may be recast, transformed, or adapted"); id. $\$ 106(2)$ (granting copyright owners exclusive right "to prepare derivative works based upon the copyrighted work").

3. See Campbell v. Acuff-Rose Music, 510 U.S. 569, 594 (1994) (holding that being more "transformative" strengthens new work's claim to qualify as non-infringing "fair use").

4. For there to be infringement, the substantial similarity must also be shown to be the result of actual copying, as opposed to mere fortuitous similarity arising though independent creation. Because it is not the focus of this Article, I will not repeat this important caveat every time I discuss what is required to render a work infringing.

5. See Alcatel USA, Inc. v. DGI Techs., Inc., 166 F.3d 772, 787 (5th Cir. 1999). 
works that have no literal similarity to the original, ${ }^{6}$ and ones that incorporate only a small amount of literal copying. ${ }^{7}$ Given that any work in which an original copyrighted work has been "recast, transformed, or adapted" may thus be regarded as a reproduction, it has even been suggested that the exclusive right to prepare derivative works is superfluous. ${ }^{8}$

Once a work has been found to be substantially similar to a copyrighted work, the question then becomes whether this (presumptively infringing) work is to be regarded a "fair use" and therefore exempted from liability. Fair use, in turn, is defined through a multifactor ad hoc balancing test, ${ }^{9}$ in which decision makers tend to grope toward two pieces of terra that seem comparatively firma, though they are not. One is the concept of "transformative" works, emphasized by the Supreme Court in Campbell $v$. Acuff-Rose Music. ${ }^{10}$ The other is the statutory directive to consider the effect of the new work on "the potential market for or value of the copyrighted work."11

Neither formulation solves the problem so much as restates it. The Campbell decision described a transformative work as one that "adds something new, with a further purpose or different character, altering the first with new expression, meaning, or message." 12 The difficulty is that the statute expressly defines derivative works as encompassing "any . . form in which a work may be recast, transformed, or adapted," including the addition of "editorial revisions, annotations, elaborations, or other modifications." 13 We therefore need a theory to tell us which "further purposes" authors should control, and which they should not. ${ }^{14}$ The market effect test is no more help, because the "potential market" for a work always includes the possibility of charging license fees to engage in whatever pu-

6. Nimmer refers to this category of works as exhibiting "comprehensive nonliteral similarity." 2 Melville B. Nimmer \& David Nimmer, Nimmer on Copyright $\$ 13.03[A][1][e]$ (2010). Standards for such similarity vary depending on the court and the nature of the works in question, ranging from a relatively stringent test requiring that both the overall expressive effect and the nature of the devices through which it is achieved be the same, to a much looser comparison of the two works' "total concept [or] feel." Compare Sheldon v. Metro-Goldwyn Pictures, 81 F.2d 49 (2d Cir. 1936) (providing example of relatively stringent test), with Roth Greeting Cards v. United Card Co., 429 F.2d 1106, 1110 (9th Cir. 1970) (providing example of looser comparison). (1985).

7. See Harper \& Row Publishers, Inc. v. Nation Enterprises, 471 U.S. 539

8. See Nimmer \& Nimmer, supra note $6, \S 8.09$ [A].

9. See 17 U.S.C. $\$ 107$ (2006).

10. 510 U.S. 569 (1994).

11. Id. at 577 .

12. Id. at 579 .

13. 17 U.S.C. $\$ 101$ (2006) (emphasis added).

14. See R. Anthony Reese, Transformativeness and the Derivative Work Right, 31 Colum. J.L. \& ARTs 467 (2008) (surveying cases and finding that few courts discuss distinction between transformativeness constituting derivative work and that constituting fair use). 
tatively transformative use is at issue. ${ }^{15}$ To decide whether a given work illicitly curtails an author's market, we first have to decide which market is rightfully hers. In the absence of a clear answer to this question, ${ }^{16}$ any risk-averse actor (i.e., one unwilling to rely on an uncertain affirmative defense as the only protection against infringement liability) must assume that a copyright owner's exclusive rights extend to virtually any secondary work discernibly incorporating expressive elements from a copyrighted work. ${ }^{17}$

We can broadly identify two ways of thinking about where to draw the needed line. One is what I will call the "internal" approach, by which I mean internal to copyright doctrine and the concepts in which it is expressed. Thinking in this vein means taking seriously the idea that such terms as "work of authorship," "derivative work," and "transformative use" can be made meaningful enough to let us look at phenomena in the real world and figure out with tolerable consistency which box they belong in, without resorting decisively to policy views about the broader consequences of which box we choose. The other approach I will call the "external" approach, by which I mean one that focuses primarily on judgments about whether the practical consequences of a particular ruling serve the broad policy purposes of copyright law-as cabined by whatever competing policy concerns we think relevant-and treats the assigning of doctrinal labels as merely the means we use to announce the results of these judgments. ${ }^{18}$ These two approaches are not mutually exclusive; all lawyers understand that legal reasoning often consists of attempting to reach an answer providing the most comfortable reflective equilibrium between the two.

When we approach problems of copyright from the external viewpoint, they tend to break down to the question of how to optimize the

15. See Sony Corp. of America v. Universal City Studios, Inc., 464 U.S. 417, 451 (1984) (stating that fair use should be negated where challenger to use of noncommercial copyright can show that, if use "should become widespread, it would adversely affect the potential market for the copyrighted work").

16. The only guidance we have at present consists of the Court's statement that the market for potential derivative uses "includes only those that creators of original works would in general develop or license others to develop." Campbell, 510 U.S. at 592.

17. See James Gibson, Risk Aversion and Rights Accretion in Intellectual Property Law, 116 YALE L.J. 882 (2007).

18. See, e.g., CCC Info. Serv. v. Maclean Hunter Mkt. Reports, Inc., 44 F.3d 61, 72 (2d Cir. 1994) (Leval, J.) (choosing to "withhold" application of "merger doctrine"-i.e., choosing to refrain from finding that disputed material was only possible means for expressing idea-because "consequences" of doing so "are too destructive of the protection the Act intends to confer on compilations, without sufficient benefit to the policy of copyright that seeks to preserve public access to ideas"); Nash v. CBS, 899 F.2d 1537, 1541 (7th Cir. 1990) (Easterbrook, J.) ("[Congress and the courts] must muddle through, using not a fixed rule but a sense of the consequences of moving dramatically in either direction."). On the distinction between internal and external viewpoints on law, see H.L.A. HART, THE CONCEPT OF LAW 100-10 (1961). 
amount of value society derives from works of authorship. Copyright law's asserted purpose is to ensure that resources whose highest-valued use would lie in the creation of works of authorship are not allocated elsewhere simply because the value of those works cannot be captured by their authors. ${ }^{19}$ Copyright, therefore, seeks to enable authors to capture the value of their works, by granting them exclusive rights to engage in certain types of activity through which that value tends to be realized. Even assuming agreement as to the broad desirability of this approach, properly calibrating the scope of the exclusive rights is extremely difficult and controversial at the margins. Copyrights prevent many valuable uses of extant works from being made, both designedly and because of transaction costs associated with their enforcement. ${ }^{20}$ Among these precluded valuable uses are creations of new works that somehow use extant works as raw materials in the act of creation. It is extremely difficult either to measure the costs of these foregone uses or to identify and measure the countervailing value of any works whose creation should be credited to a given marginal increment of exclusivity granted to authors.

While the external approach to copyright reaches an empirical impasse, ${ }^{21}$ the internal approach looks like sheer quicksand. A work of authorship is an intangible entity, undefined by the statute, and capable of description on an indefinite number of levels of abstraction. The character of such a work can be altered by degrees along numerous dimensions, with resulting incremental and cumulative effects offering no clear points of demarcation by which to distinguish when one work becomes a different work. Finally, people create and use works of authorship for highly varied purposes, and the enterprise of deciding which "purposes" of a work are its "real" ones seems unlikely to generate objective consensus.

Despite the problems just described, I want to suggest that the internal approach to copyright is not as hopeless as it might seem. I do not claim that it will ever suffice to answer all the hard questions in fully satisfactory ways or entirely obviate the resort to external reasoning. My claim is more modest-that we could do a better job than we currently do of giving consistent meaning to the basic concepts of copyright doctrine, and that doing so could make some questions less hard than they seem now. The reason I think this is because all the problems of indeterminacy described in the above paragraph apply equally to tangible objects. Philosophers

19. See Nash, 899 F.2d at 1541 ("[T] o deny authors all reward for the value their labors contribute to the works of others . . . will lead to inefficiently little writing ....").

20. See id. at 1540 (" $[\mathrm{A}]$ ny rule requiring people to compensate the author slows progress in literature and art ....").

21. See William M. Landes \& Richard A. Posner, The Economic Structure of Intellectual Property Law 9 (2003) (“[N]either economic theory nor empirical evidence enables a ringing endorsement of any complete body of intellectual property law other than trademark law .... [The] belief that without legal protection the incentives to create such property would be inadequate . . . cannot be defended confidently on the basis of current knowledge."). 
have quibbled for centuries over the meaning of identity in a world where matter and form are in constant flux. More importantly for our purposes, so have lawyers. The traditional property law dealing with mundane objects has faced the same problems of ownership across transformation plaguing us in copyright, and it has addressed them through what has come to be called the doctrine of accession. ${ }^{22}$ Properly construed, this doctrine provides insights that could help us to place objective limits on the scope of the value that copyright owners may properly claim as their own.

\section{B. Is Property Really the Source of the Trouble?}

The suggestion that we might ameliorate copyright doctrine by treating it more similarly to traditional property is anathema to many commentators on copyright law, who think the problem is precisely too much traditional property talk. ${ }^{23}$ Throughout his recent book, Copyright's Paradox, Neil Netanel argues that "Blackstonian" or "propertarian" thinkingtwo terms he uses more or less interchangeably-are the root cause of virtually all of copyright's ills. ${ }^{24}$ Netanel contrasts the vision of copyright as a "full-fledged property right" giving owners "a broad "sole and despotic dominion' over each and every possible use of a work" with a competing view of copyright as "a limited government grant narrowly tailored to serve a public purpose." ${ }^{25}$ Commenting on this critique, Shyamkrishna Balganesh diagnoses the problem as lying in two interconnected elements of the Blackstonian understanding of property: "absolutism," defined as "the idea that property has no limits," and "essentialism," defined as the idea that once an entitlement is designated as a form of property, its owner is allowed to exercise the exclusionary right for any reason whatsoever. ${ }^{26}$

I agree with Netanel, Balganesh, and the many others who believe that copyright law, as currently applied, often gives excessively broad scope to the exclusive rights of copyright owners, enabling them to exercise control over actions that should not properly be regarded as infringing. I want to suggest, however, that the problem lies not in copyright's propertarian nature but in misunderstandings (apparently shared by both copyright expansionists and their critics) about what that nature ought to

22. See generally Earl C. Arnold, The Law of Accession of Personal Property, 22 Colum. L. Rev. 103, 103-07 (1922); Thomas W. Merrill, Accession and Original Ownership, 1 J. Legal ANalysis 459 (2009); Henry E. Smith, Intellectual Property as Property: Delineating Entitlements in Information, 116 YALE L.J. 1742, 1766-77 (2007).

23. See Adam Mossoff, Is Copyright Property?, 42 San Diego L. Rev. 29, 32 (2005) (pointing to work of Doc Searls and Siva Vaidhyanathan as primary examples of impulse to banish talk of property from copyright discourse altogether). The same theme pervades William Patry, Moral Panics and the Copyright Wars (2009).

24. See Neil Netanel, Copyright's Paradox passim (2008).

25. Id. at 6-7.

26. See Shyamkrishna Balganesh, Debunking Blackstonian Copyright, 118 YALE L.J. 1126, 1134 (2009). 
entail. ${ }^{27}$ In particular, I want to drive a wedge between the concept of propertarian copyright and the assertion that copyright should be "expansive"-i.e., that it should confer exclusive rights over every work discernibly incorporating expressive content from the owned work. ${ }^{28}$ This article presents an unabashedly propertarian version of copyright, but argues that traditional property doctrines actually contain precisely the kinds of internal limitations on the scope of owners' claims that Netanel and others would like to see. ${ }^{29}$ Furthermore, because property doctrine (if rightly understood) imposes those limitations internally and based on norms of social intelligibility, it may enable people-owners, users, third parties, judges-to discern them more readily than does an approach requiring one to engage in external weighing of empirically unmeasurable factors in order to decide where the lines should be. In fact, one might lay the blame for copyright's overexpansion as easily at the door of ad hoc instrumentalist reasoning intended to further a "public purpose" as at the door of property talk. It is such reasoning, after all, that eternally frets over the prospect that any failure to capture some increment of value proximately arising from use of a copyrighted work will "reduce incentives to create."30

Nor does treating copyright as a propertarian entitlement require one to deny that it is "a limited government grant narrowly tailored to serve a public purpose." 31 I will not argue here over whether copyright protects interests having any normative force that can be justified without reference to state power. Even conceding that copyright is entirely a creation of the government to serve a public purpose, the question remains

27. Netanel acknowledges early on in his book that this Blackstonian vision does not accurately represent the law of property and trains his sights instead on the way in which property rhetoric based on this vision is actually used by copyright expansionists. See Netanel, supra note 24, at 7. Unfortunately, using the label "propertarian" to describe this rhetorical position tends to reinforce the erroneous notion that property doctrine actually does support expansionist claims. This has two pernicious effects: legitimizing expansionism in the eyes of those with a strong commitment to property rights and delegitimizing property in the eyes of those who deplore expansionism. See Hanoch Dagan, Property and the Public Domain, 18 YALE J.L. \& HUMAN. 84, 87 (2006) (making similar point with regard to work of Lawrence Lessig and arguing that "friends of the public domain should embrace property, rather than fight it").

28. Netanel's terminology equates the two, as illustrated by his chapter "The Propertarian Counter-Argument," which collects and rebuts various economic arguments as to why an expansive copyright scope is desirable. See Netanel, supra note 24, at 154 ("Much of the propertarian argument-the notion that an expansive copyright would actually enhance expressive diversity-has an air of unreality.").

29. I am not the first to argue in this vein. See, e.g., Michael Carrier, Cabining Intellectual Property Through a Property Paradigm, 54 DukE L.J. 1 (2004); Dagan, supra note 27.

30. See, e.g., Sony Corp. of America v. Universal City Studios, Inc., 464 U.S. 417,480 (1984) (describing risk that "depriving authors of their monopoly will reduce their incentive to create").

31. See Mossoff, supra note 23, at 34 (pointing out that all property rights can be characterized in this way). 
whether that purpose is best served by the mechanism of conferring a property right, and whether there is anything about the logic of property rights that inherently prevents them from qualifying as "narrowly tailored."

To be sure, if by narrowly tailored one means that there will be no instance in which a copyright owner is allowed to assert rights not immediately advancing the goals of the institution, then a propertarian approach is not narrowly tailored. Such a standard, however, ignores the problem of information costs and the advantages of well-defined rights in rem for "solving problems wholesale and coordinating the activities of often-anonymous actors." 32 The optimal amount of successful holdout is not necessarily zero, ${ }^{33}$ even where the result of holdout is the suppression of speech, and even if, as for Netanel, the advancement of free speech interests is one's primary concern. Speech is suppressed by uncertainty as well, and to the extent that the rights of downstream creators depend on post hoc interest balancing-even if that balancing is animated by the principles Netanel and Balganesh prefer-the dynamic of rights accretion will tend to freeze out speech even without expansionist property rhetoric to lead the way. ${ }^{34}$ The propertarian strategy is to buy some certainty at the cost of some narrowly tailored overinclusion. There will be room for argument as to how exactly we should do this, and whether the tradeoff is a good bargain. This Article will not attempt to win that argument decisively. It will attempt to show that there is a big difference between the overinclusion countenanced by property doctrine and the notions of absolutism and essentialism, which correspond to little about actual property doctrine other than Blackstone's infamously hyperbolic characterization of it. ${ }^{35}$ It will also offer a model of copyright doctrine that illustrates in some detail how a propertarian approach might actually better solve many of the problems posed by Netanel than an outright rejection of the logic of property altogether.

Part II provides an account of the logical underpinnings of traditional property doctrine by which property serves primarily to protect the interest all individuals have in being able to make reliable beneficial use of particular things. The propertarian strategy for defining and communicating the reciprocal duties needed to achieve this is to make use of in rem rights whose content can be understood by third parties without reference to the subjective use preferences of owners. The "right to exclude" is not

32. Henry Smith, Mind the Gap: The Indirect Relation Between Ends and Means in American Property Law, 94 CORNell L. Rev. 959, 963 (2009).

33. See id. at 969.

34. See generally Gibson, supra note 17.

35. See 2 William Blackstone, Commentaries *2 (describing property as "sole and despotic dominion which one man claims and exercises . . . in total exclusion of the right of any other individual in the universe"); Richard A. Epstein, Intellectual Property: Old Boundaries and New Frontiers, 76 IND. L.J. 803, 804 (2001) (" $[\mathrm{T}]$ o look closely at all the forms of property that have existed even before reaching intellectual property is to realize that Blackstone engaged in injudicious overgeneralization ...."). 
an absolutist end in itself, but a prophylactic and defeasible bright-line rule that applies only to a well-defined class of consumptive uses taken with regard to a well-defined thing. Beyond those limits, owners are not permitted to exclude others categorically from actions that conflict with idiosyncratic use preferences, or from actions that otherwise derive value from the owned thing.

Part III examines the problem of transformation in tangible property, which arises when an owned thing undergoes some physical event, arguably changing it into a different thing. Tracing the doctrines of specificatio and accessio from Roman through common law, I highlight ways in which the logic of in rem rights can be implemented to place objective, socially intelligible boundaries on the identities of owned things. These limits tend to focus on form and conceptual identity, categories that serve as proxies for utility but define it according to social norms rather than an owner's subjective use preferences. These limits prevent owners from asserting such preferences in order to appropriate value created by others. Concern about rewarding opportunism led the common law to expand the range of transformations that would remain within an owner's right to exclude, ultimately prompting a countervailing move by equity to restrain opportunism by owners. Because transformation of a work of authorship does not necessarily harm an owner's ability to exploit the original work, this concern carries far less weight in copyright.

Part IV shows how the logic of in rem rights might be applied to copyright with non-expansionist results. Here the protected interest is that of an author in realizing exchange value based on enabling others to make beneficial use of a work of authorship. The in rem approach demands clear boundaries around the identity of this work of authorship, boundaries that have been obliterated by current copyright doctrine finding substantial similarity based on fragmentary similarity of expression. I propose to define a work of authorship in terms of a coherent expressive experience designed by the author, and show that the statutory definition of derivative work covers only works that serve as vehicles to deliver the same experience to a different audience. Putative "copies" that are not tailored to facilitate beneficial use of the work as conceived by the author, but rather to communicate second-order information, or to give rise to expressive experiences radically discontinuous from the ones the author designed, therefore, fall outside the author's right to exclude, making resort to fair use doctrine unnecessary. I attempt to spell out the implications of this approach to copyright, illustrating how an in rem approach might provide marginally clearer results in a variety of contexts. I also show how this approach could eliminate many of the problems of suppressed speech highlighted by Netanel and others, while identifying some other popular uses that would remain within the scope of authors' rights. 


\section{Property}

\section{A. In What Sense Is Exclusion the "Essence" of Property?}

The argument for banishing property concepts from the realm of copyright might be paraphrased something like this:

Copyright seeks to achieve a carefully calibrated balance between the need to provide remuneration to authors and the need to preserve the freedom of others to use and benefit from works of authorship. Property rights are incompatible with this goal, because property consists of broad exclusionary rights whose exercise is by definition unlimited by reference to any underlying principle. $^{36}$

The description of property as essentialist, in other words, implies that from a property perspective the right to exclude is an end in itself. Once we decide that an author owns a work, propertarian logic leads-it is assumed-to the ineluctable conclusion that the author has an absolute right to exclude others from anything that can be termed a "use" of the work.

To describe exclusion as the "essence" of property is accurate in one sense: exclusion is the central and characteristic strategy by which the institution of property seeks to achieve its goals. ${ }^{37}$ It is also highly misleading, however, because it obscures the fact that property actually has goals beyond exclusion that place limits on the right to exclude. ${ }^{38}$ Property, too, is an attempt to achieve a carefully calibrated balance between protecting an interest and preserving freedom of action. Exclusion is not an end in itself, ${ }^{39}$ but part of the strategy for achieving this balance. ${ }^{40}$

Can the despotic Blackstonian right to exclude possibly be described as narrowly tailored rather than absolute and essentialist? I will argue that it can by examining the reasons why we have it and the limitations we impose on it. The account of property rights given here is analytical, not historical. I believe it to be consistent with traditional property doctrine (by which I mean Roman, civilian, and Anglo-American common law) and useful in rendering it intelligible, but make no claim that the particular

36. See generally Balganesh, supra note 26.

37. See generally Thomas W. Merrill, Property and the Right to Exclude, 77 NeB. L. Rev. 730 (1998); Henry E. Smith, Property and Property Rules, 79 N.Y.U. L. REv. 1719 (2004).

38. See Adam Mossoff, What Is Property? Putting the Pieces Back Together, 45 ARIz. L. REv. 371 (2003) (tracing history of right to exclude in natural law theory and showing it to be secondary to rights of use); see also infra note 48.

39. See J.E. Penner, The Idea of Property in Law 70 (1997) ("No one has any interest in merely excluding others from things, for any reason or no reason at all."); id. at 71 ("Any true right of an owner to exclude others must be understood to be an auxiliary right which enforces or protects the right to property.").

40. See id. ("Any true right of an owner to exclude others must be understood to be an auxiliary right which enforces or protects the right to property."). 
chain of logic presented corresponds in any chronological sense to either the anthropological development of property as a social institution or to the course of development of the common law. The purpose of the inquiry is to examine the way in which the mechanism of property rights seeks to achieve its goals. This will provide the basis for (in Part III) an interpretation of property law's response to transformations of the object of ownership, and finally (in Part IV) for an exploration of the extent to which a similar approach might fruitfully serve the ends of copyright law.

\section{B. Beneficial Use and Consumptive Use}

The interest that underlies property is the interest in using things. ${ }^{41}$ Before attempting to explain the relationship between that interest and the right to exclude, it is worth being more precise about what we mean by the word "use." Much of the source of the expansionist error in copyright can be found in a failure to pay attention to various types of use and their implications for property law.

I want to distinguish between two dimensions along which we might term a given action a use of a thing. The first is beneficial interaction, by which I mean derivation of benefit from direct interaction with the thing, where the specific benefit obtained depends upon the nature of the thing. Thus, climbing a tree, sleeping against its trunk, chopping it down for lumber, or admiring its living beauty from a distance are all beneficial uses of the tree. The second dimension of use is consumption, by which I mean actions that somehow diminish (whether temporarily or permanently) the thing's potential usability. There are two ways in which a use can be consumptive: it can occupy the thing in such a way as to obstruct or interfere with other potential uses (e.g., Goldilocks sleeping in Little Bear's bed), or it can alter the thing so as to eliminate (or diminish the potential benefits from) certain of its potential uses (e.g., Goldilocks breaking Little Bear's chair). In this sense, all the uses of the tree mentioned above are consumptive, save only admiration from afar.

To avoid possible confusion, let me be clear that what I term a "consumptive use" does not necessarily "consume"-i.e., diminish the physical substance of-the thing itself. It does, however, necessarily consume opportunities for the thing to be used in other ways and/or by other people. It is also worth noting that my use of the term "consumptive" means something related to but distinct from the term "rival" (or "rivalrous"), which is typically predicated of goods, not uses. ${ }^{42}$ The tree is a rival good, in that

41. See id. (defining right to property as "a right to exclude others from things which is grounded by the interest we have in the use of things" (emphasis omitted)).

42. See, e.g., David L. Weimer \& Aidan R. Vining, Policy Analysis: Concepts AND Practice 72 (4th ed. 2005) (defining rival goods as ones whose consumption by one consumer prevents simultaneous consumption by other consumers). A good is "rival" in this sense to the extent that it is susceptible to what I call "consumptive" use. 
chopping it down will necessarily prevent the tree lover from enjoying it. But it would be more precise to speak of the lumberjack and the tree lover as engaging in rival-i.e., noncompossible-uses. My term "consumptive" takes the analysis a step further, highlighting the sometimes asymmetrical nature of this rivalry. The lumberjack's use, by its own force, categorically excludes that of the tree lover. The reverse is not true. Certainly, if we wish to protect the nature lover's ability to make his preferred use of the tree, we will have to categorically exclude the lumberjack. Nevertheless, the nature of the tree lover's actual interaction with the tree does not of its own force diminish the lumberjack's or anyone else's ability to make any other simultaneous or future use of it. It is therefore nonconsumptive. Consumptive uses can be further subdivided into possessory uses of a thing-i.e., those involving immediate physical occupation or manipulation of the thing-and non-possessory uses that alter it without occupation, such as pollution or other nuisances. ${ }^{43}$

Let us also head off any possible confusion about the term "beneficial use." What I term beneficial uses are not necessarily welfare maximizing, or otherwise beneficial to society at large. They are merely acts by which the actor derives some subjective benefit from the nature of the object. For example, if I derive perverse aesthetic pleasure from blowing smoke onto your land and watching it gradually blacken the trees and buildings there, I am using the property in a way that is beneficial, consumptive, and non-possessory. If, on the other hand, my factory sends out pollution to the world at large, and I am entirely indifferent as to where it goes-if the benefit I get from my activities would be unaltered were there nothing around to be affected by the pollution at all-then I am making consumptive but non-possessory and non-beneficial use of any property affected by the pollution. We can chart the different categories of use as follows.

Categories of Use of Tangible Objects

\begin{tabular}{|l|l|l|}
\hline Type of use & Beneficial & Nonbeneficial \\
\hline Consumptive & $\begin{array}{l}\text { Possessory: e.g., cultivating, devel- } \\
\text { oping, grazing, or foraging over } \\
\text { a plot of land; holding or } \\
\text { directly manipulating a chattel. } \\
\text { Nonpossessory: Intentional } \\
\text { nuisance. }\end{array}$ & $\begin{array}{l}\text { Possessory: e.g., trampling of } \\
\text { crops while driving cattle from } \\
\text { point A to point B, } \\
\text { Nonpossessory: Non-intentional } \\
\text { nuisance; pollution. }\end{array}$ \\
\hline $\begin{array}{l}\text { Non- } \\
\text { Consumptive }\end{array}$ & $\begin{array}{l}\text { Drawing benefit (e.g., pleasure, } \\
\text { information) from the thing by } \\
\text { means of perception (e.g., sight- } \\
\text { seeing), contemplation (e.g., } \\
\text { knowledge of a resource's con- } \\
\text { servation), or communication } \\
\text { (e.g., discussing the thing with } \\
\text { others). }\end{array}$ & Non-use. \\
\hline
\end{tabular}

43. See Christopher M. Newman, Patent Infringement as Nuisance, 59 CATH. U. L. REv. 61, 93-102 (2009). 
Note that the categories of use, as I have defined them, do not include all activities by means of which one enjoys utility that is in some sense derived from the owned thing. Beneficial use requires some form of direct interaction-i.e., action having the thing as its object-even if it is only contemplation of the thing's existence. There are plenty of benefits we derive from things that do not involve even such an attenuated notion of use. If you build a factory in my town that leads to an increased labor population, and I build a restaurant or other business that caters to these people, I am deriving benefit that is, at least in part, based on the existence of the factory and your investment in building it. You might even be moved to describe me as "free riding" on your investment. I think no one, however, would describe me as "using" your factory. In the realm of tangible property, to use a thing and to "derive value proximately arising from its existence" are clearly understood to be two different matters.

The distinctions between these kinds of use (and non-use) are important, because, as we shall see, the right to exclude pertains only to one of them-consumptive use. Indeed, in its strict form, it pertains only to possessory uses. The right to exclude does not extend to either beneficial uses per se (except to the extent that they are also consumptive uses) or nonuses that nevertheless derive value from the owned thing. The problem with copyright doctrine is that it has failed to provide a clear understanding of either the thing in question or the lines between these kinds of use, ${ }^{44}$ and has thus wound up tending to equate all derivation of value with possessory use.

\section{From Rights to Use to Rights to Exclude}

Property is a response to a few basic facts of human existence: To survive, people need to make beneficial uses of things. To pursue any sustained life activities, they need to be able to plan, which means being able to rely on their ability to make beneficial uses of particular things in the future. ${ }^{45}$ My ability to make beneficial use of given things, however, is vulnerable to preemption by consumptive uses of those things by others, as is theirs by mine. Property is a social institution through which we attempt to mediate this problem by taking on reciprocal duties to refrain from certain consumptive uses of things in order to allow others to make certain beneficial uses of those things. We define and communicate these duties by means of the concept of property rights.

At a minimum, then, a property right must designate a thing, an owner, and a use of the thing that the owner is entitled to make. This right will then give rise to a correlative duty on the part of others to refrain

44. For a further discussion of the copyright doctrine, see infra notes 170-74, 234-43 and accompanying text.

45. See John Simmons, The Lockean Theory of Rights 275 (1992) ("Self government is only possible ... if the external things necessary for carrying out our plans can be kept, managed, exchanged (etc.) as the plans require."). 
from any consumptive uses of the designated thing that interfere with the owner's entitled use. We might call the owner's property right a "right to exclude," but it excludes others only from actions directly conflicting with the entitled use. An example would be a right-of-way easement, which is a usufructuary right entitling its owner to traverse a piece of land. This right imposes a duty on others not to obstruct the owner's passage, but does not otherwise purport to exclude others from use of the land. It thus preserves the owner's ability to make his entitled use while imposing restraints on others' freedom of action that are as narrowly tailored as possible. The question is why all property rights are not defined in this way. What considerations justify the move from this minimally intrusive form of property right to a model in which the paradigmatic form of ownership is not the usufructuary right but the fee simple?

In the minimal version of property rights described above, each property right protects only the ability to engage in some specified use of the thing. In theory, there could be as many such rights as there are potential beneficial uses of the thing, each of which could be allocated to a different owner. Each such right would be in personam, in that the content of the correlative duty would be specific to the individual owning the right. ${ }^{46}$ If A owns a right of way, each of us has a duty not to interfere with A's use of it to traverse the land. Since a duty thus defined doesn't purport to exclude us categorically from any use of the land, including uses that might temporarily obstruct passage, compliance with this duty requires us to know something about A's intended exercises of his right. While each such property right is thus minimally intrusive in terms of the number of acts by duty-holders that it rules out, it imposes high information costs to figure out which acts those are. If there are many owners with rights to make different beneficial uses of the same thing, the information costs may quickly become paralyzing. ${ }^{47}$

The minimal version of property rights gives rise to another problem as well. Whenever we divide up the potential beneficial uses of a single thing among different owners, we have to make sure that we restrict any consumptive uses so allocated in such a way as not to preclude other uses allocated to someone else-otherwise our system of property rights will create conflict rather than prevent it. For a wide range of resources, the only practical way to achieve this will be to vest some ultimate decision maker with all the beneficial use rights pertaining to a given thing and let that individual decide how to assign them. ${ }^{48}$ The first step toward the

46. See Penner, supra note 39, at 23-31 ("The criterion [of a right in personam] is whether the duty is in any way specific to particular individuals in terms of its content.").

47. See Merrill, supra note 22, at 476.

48. Note that not all resources call for this form of ownership, and property theory has never asserted that unitary ownership of things is the appropriate solution to every conceivable use conflict. See Epstein, supra note 35, at 809 (noting that "fee ownership is not some universal rule even for land"); see also id. at 810 (describing how Blackstone understood private interests in water to be largely 
broad right to exclude is the recognition of this type of ownership, one conferring the presumptive right to make (or assign) any potential beneficial use of a given thing at any time ${ }^{49}$ - what the Romans called ius utendi fruendi abutendi. ${ }^{50}$

This first step does not cover the whole distance, however. Strictly speaking, the only duty that follows from an owner's right to make any desired beneficial use of the owned thing is still an in personam duty to refrain from interfering with those uses the owner actually attempts to make. If you are not making any use of your backyard one night, and I camp out there without leaving a trace, I have not interfered with any use of yours and so have not violated your right to use. No harm, no foul. To justify the sort of right to exclude that turns my harmless campout into a trespass, we need another step.

Again, the step has to do with information costs. For property rights to work, the people saddled with duties by them (i.e., all of us) have to be able to figure out which actions we are required to avoid. For me to decide whether it is alright to camp out in your backyard, I have to somehow figure out whether this will interfere with any planned use of yours. Your plans may not be apparent to others, which means that I am likely to err in gauging them and hence to actually interfere even if I think I am not. Even if you had no plans, you may have a spontaneous desire to use your yard that my presence will interfere with even if I voluntarily leave as soon as you make your need known. To some extent, the very fact that you know this is a possibility will interfere with your use and enjoyment of your yard. These ambiguities will also be troublesome if we get into a dispute over whether my actions violated your property rights, in which case some

usufructary, resulting in open-access system with restrictions on extent to which water could be withdrawn and appropriated). Such usufructary rights are still a form of property right following from the underlying interest in making reliable beneficial use of things. Their existence provides another illustration that nothing about propertarian reasoning requires the embrace of absolutism or "essentialism."

49. On the lexical priority of the right to assign use over the right to exclude, see Eric R. Claeys, Property 101: Is Property a Thing or a Bundle?, 32 Seattle U. L. Rev. 617, 631 (2009) (defining property as "right to determine exclusively how a thing may be used"); Larissa Katz, Exclusion and Exclusivity in Property Law, 58 U. TORONTO L.J. 275, 275 (2008) (arguing that "central concern" of structure of property ownership "is not the exclusion of all non-owners from the owned thing but, rather, the preservation of the owner's position as the exclusive agenda setter for the owned thing"); Mossoff, supra note 38, at 393 ("It is not exclusion that is fundamental in understanding property; the fountainhead of property is found in possession, i.e., the use of something, and it is this fact that serves as the primary element in the concept property."); J.E. Penner, The "Bundle of Rights" Picture of Property, 43 UCLA L. REv. 711, 742 (1996) (defining right to property as "the right to determine the use or disposition of an alienable thing in so far as that can be achieved or aided by others excluding themselves from it").

50. See Max Radin, Fundamental Concepts of the Roman Law, 13 CAL. L. REv. 208, 209 (1925) (stating three verbs denote different intensities of use, depending on whether they preserve resource (utendi), diminish it (fruendi), or consume it completely (abutendi)). 
judge or jury will have to figure out what uses you intended or tried to make and whether my actions actually impeded them or not.

To avoid these problems, we move from in personam duties to avoid interfering with owners' specific uses, to a model of in rem ownership, in which property rights pertain, not to beneficial uses, but to the thing itself, and the duty they impose is to avoid making consumptive uses of the owned thing at all. ${ }^{51}$ No longer do I need to know anything about the identity or intended uses of any owner to ascertain what my duties are with respect to any thing. As J.E. Penner puts it, "Norms in rem establish the general, impersonal practices upon which modern societies largely depend. They allow strangers to interact with each other in a rule-governed way, though their dealings are not personal in any significant respect." 52 Norms in rem impose a single, uniform set of default duties that apply to every member of society in their interactions with every owned thing they encounter.

It is this in rem exclusion from the thing that we normally refer to as the owner's right to exclude. The advantage of recognizing such a right is that it is a bright-line rule, easy to obey and enforce, letting us know with a high level of confidence when property rights have been violated. ${ }^{53}$ Like all bright-line rules, it will be overinclusive to some extent-it will prohibit me from doing certain things that would not really interfere with your ability to use your property at all. If this over-inclusion is to be justified, we have to calibrate the scope of the right to exclude so as not to restrict my freedom of action to an extent unjustified by probable violations of your use rights and the costs of identifying them. We achieve this by applying the strict right to exclude to possessory uses only. ${ }^{54}$ Possessory uses of a thing are highly likely to interfere directly with uses chosen by the thing's owner, whether actual, planned, or spontaneously arising. Possessory uses are also easy to detect and to avoid. To be sure I am not violating your right to exclude, I need only stay out of your yard. To decide whether I did violate it, a judge need only ascertain whether I entered. Finally, ex-

51. See PenNer, supra note 39, at 26-31 ("A duty in rem is a duty not to interfere with the property of others, or some state to which all others are equally entitled."). Again, I am not claiming that there was any literal historical progression of this kind, but trying to explain the logic that makes norms in rem an improvement over multitudinous duties in personam, despite the fact that recent intellectual history has moved in the opposite direction. See Thomas W. Merrill \& Henry E. Smith, What Happened to Property in Law and Economics?, 111 YALE L.J. 357, 360-66 (2001) (showing in rem to have been traditional conception of property rights until realists' recasting of property as "bundle" of in personam rights).

52. Penner, supra note 39 , at 30.

53. See Smith, supra note 22, at 1755.

54. Restatement (SECOND) OF TORTs $\$ 158$ (1965) ("One is subject to liability to another for trespass, irrespective of whether he thereby causes harm to any legally protected interest of the other, if he intentionally: (a) enters land in the possession of the other, or causes a thing or a third person to do so, or (b) remains on the land, or (c) fails to remove from the land a thing which he is under a duty to remove.") 
clusion of possessory uses imposes limited and tolerable constraints on my scope of action; I must keep my mitts off your things, but am free to acquire and use my own.

To the extent that the description of property as essentialist makes sense, it is with reference to the owner's right to exclude possessory uses of the owned thing. Within this realm, the owner is indeed "allowed to exercise the exclusionary privilege/right that is central to it, regardless of any underlying reason." 55 This is because inquiring into the owner's reasons for wishing to exercise the right would put us back into a world of in personam obligations, in which the content of the duty imposed by one person's property rights would not be ascertainable without knowledge of the owner's needs and intentions. Even so, the owner's dominion is not absolute, as it can be qualified by limited usufructary rights in the form of easements, as well as the doctrine of necessity, which defines circumstances in which the owner's right to exclude must give way. ${ }^{56}$

Note, too, that the right to exclude is under- as well as overinclusive. Possessory uses are not the only ones that threaten to interfere with an owner's ability to make beneficial use of the owned thing. Consumptive non-possessory uses can do so as well. In a world of truly absolutist, essentialist property rights, all such uses would count as trespasses, and your despotic dominion would extend to forbidding my backyard barbecue if you objected to the odors wafting over into yours. We do not subject these uses to the bright-line right to exclude, however, for several reasons. First, the likelihood of actual interference is far less categorical than for possessory ones. Second, many non-possessory consumptive uses (which include all spillover effects resulting from the uses of nearby things) are likely to be far more difficult to foresee, detect, and avoid with perfect precision and consistency. Finally, a bright-line prohibition of all non-possessory consumptive uses would impose severe constraints on the freedom of action of the owner's neighbors, limiting their ability to make beneficial use of their own property.

Far from allowing owners to exercise their rights to exclude for any reason, we require owners who complain of non-possessory consumptive uses (i.e., nuisances) to show not only actual interference, ${ }^{57}$ but that the use interfered with is one the community regards as falling within reasonable expectations of unimpeded use. ${ }^{58}$ Once we leave the boundaries of the strict right to exclude, the owner's idiosyncratic or unimplemented

55. Balganesh, supra note 26, at 1134.

56. See Ploof v. Putnam, 71 A. 188, 189 (Vt. 1908) ("One assaulted and in peril of his life may run through the close of another to escape from his assailant."). Another common example is docking a ship in a storm. See id. (providing another doctrine of necessity example).

57. See Restatement (Second) of Torts $\S 821 \mathrm{~F}$ (1977) (stating that liability for nuisance exists "only to those to whom it causes significant harm").

58. See id. (stating harm must be "of a kind that would be suffered by a normal person in the community or by property in normal condition and used for a normal purpose"). 
use preferences are no longer strictly protected. In part this is to avoid opportunism by property owners who might seek to extract value from the productive activities of neighbors simply by claiming some intended use that those activities interfered with. ${ }^{59}$ More fundamentally, however, we can understand the objective constraints on nuisance claims as following from the in rem model of property rights. A duty to avoid significant interference with actual, objectively reasonable uses is one whose contents dutyholders can readily understand without any need for information about owners and their subjective preferences. The distinction between trespass and nuisance exhibits the narrow tailoring of the right to exclude.

The in rem principle is thus a two-edged sword when it comes to the amount of discretion afforded to owners: on the one hand, they get a near absolute right to exclude possessory uses, yet this is counterbalanced on the other by a more porous right that allows exclusion only of those nonpossessory ones meeting objective standards of interference. As we shall see in Part III, the logic of in rem rights also places objective limits on the extent to which an owner can assert continued ownership over a thing when it undergoes transformation.

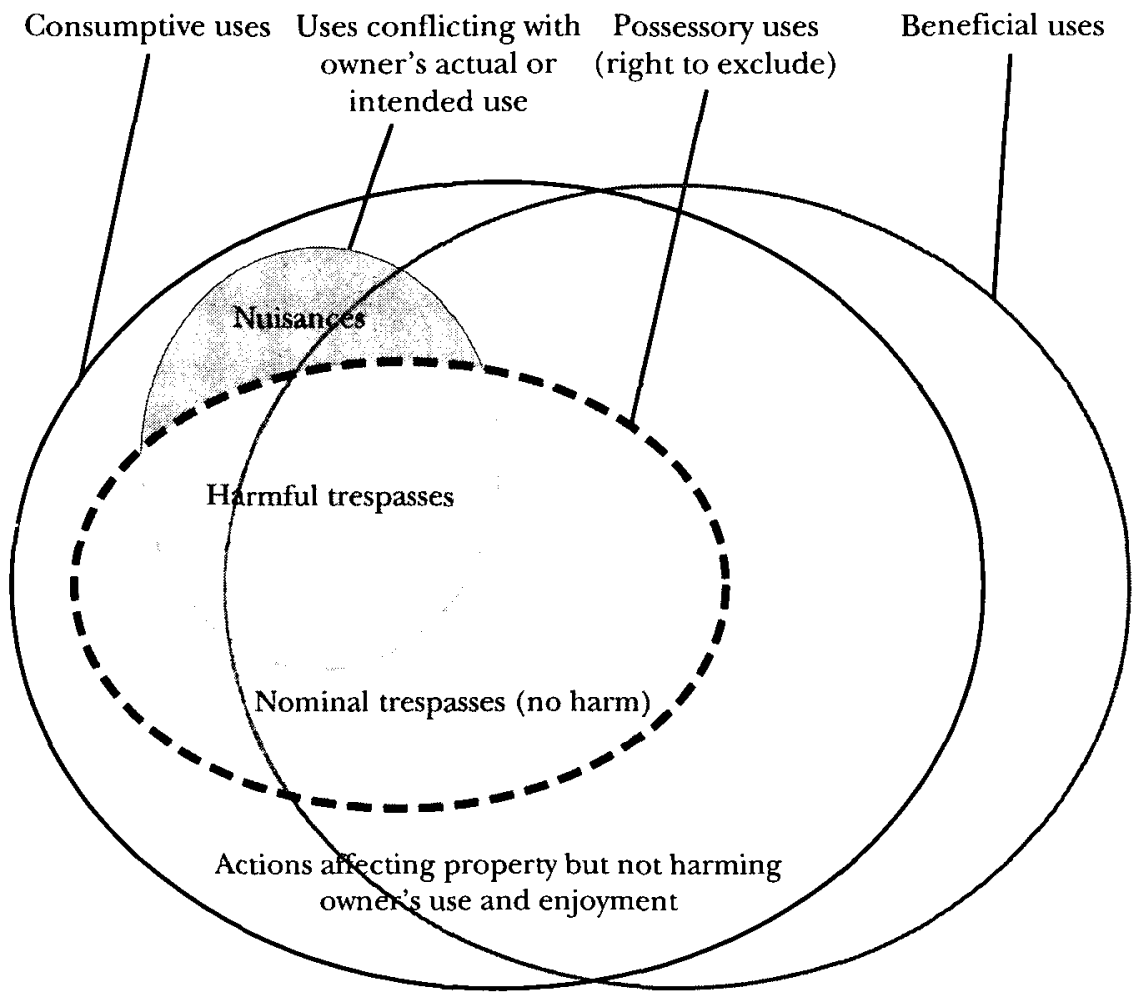

59. See Newman, supra note 43 , at 93-103. 


\section{TRANSFORMATION}

Property rights are important "because they establish a basis of security of expectation regarding the future use and enjoyment of particular resources."60 The key word here is "particular." Part of what it means to say that property rights are in rem is that they pertain to a particular thing-a res-and protect the owner's ability to assign uses to that particular thing. Only when legal regimes seek to protect this ability concretely, by prohibiting (and, where necessary, forcibly reversing) non-consensual transfers, are they said to apply "property rules." 61 To apply a property rule is to require that the owner of a thing be restored to exclusive and undisturbed possession-in the case of land, by the eviction of all trespassers and cessation of all nuisances; in that of chattels, by their return to the owner's physical control. This is in contrast to so-called "liability rules," which do not seek to preserve or restore the preexisting relationship between people and a particular thing, but rather to require a particular person who disrupts that relationship to compensate the person harmed by the disruption. ${ }^{62}$ Such compensation necessarily takes the form of some other thing, deemed by some outside observers to have equivalent value to the one taken. The obligation to make such compensation is imposed in personam-applicable only to the wrongdoer.

Though the Supreme Court has asserted that "the creation of a right is distinct from the provision of remedies for violations of that right," 63 this is not quite accurate; the nature of the remedy provided determines the content of the right. ${ }^{64} \mathrm{~A}$ right to assign uses to a particular identified thing is quite different from a right to assign uses to some thing whose ultimate identity is contingent on choices made by others in the future. Just as the in rem principle generally rules out inquiry into an owner's subjective intent in deciding whether there is a use conflict, it rules out inquiry into an owner's subjective valuation when deciding how to remedy one. Of course, this leaves the possibility of providing compensation according to some objective valuation. The problem with this is that such objective valuations will systematically fail to reflect both the subjective value owners place on their property, and the superior understanding they

60. Merrill \& Smith, supra note 51, at 363 .

61. See Guido Calabresi \& A. Douglas Melamed, Property Rules, Liability Rules, and Inalienability: One View of the Cathedral, 85 Harv. L. Rev. 1089, 1092 (1972). Of course, the law cannot infallibly prevent or reverse non-consensual transfers. All it can do is try to bring about these results by threatening wrongful possessors with penalties sufficient to nullify any gain from the wrongful transaction.

62. See id.

63. eBay Inc. v. MercExchange, L.L.C., 547 U.S. 388, 392 (2006).

64. See Eric R. Claeys, Exclusion and Exclusivity in Gridlock, 53 ARIz. L. Rev. 9 (2011) (discussing Jules L. Coleman \& Jody Kraus, Rethinking the Theory of Legal Rights, 95 YALE L.J. 1335 (1986)). 
are likely to have of its entrepreneurial value. ${ }^{65}$ This discrepancy creates incentives for opportunistic takings, thus undermining the very reliability of stable beneficial use that the institution of property is meant to protect. 66

We live in a mutable world, however. If we are really going to insist that property rights pertain to specific physical things, and we intend to enforce owners' claims to exercise exclusive possession of those things, sooner or later we will be forced to decide whether some claimed thing is still the same thing in which ownership was acquired, or whether instead it has turned into-been replaced by-some other thing. We are going to need a theory of "thingness."

\section{A. The Basic Legal Structure of the Transformation Problem}

The legal scenarios in which we confront this problem (we will call them "transformation scenarios") all involve the following common elements:

1) an owned thing;

2) some sort of transformative event involving the owned thing;

3) the emergence from this event of a second thing asserted to have continuous identity with the original owned thing but that also differs significantly from it; and

4) a claim by the owner that his property rights in the original thing now encompass the new thing.

Such scenarios require us to decide whether the owned thing still exists, and if so whether the "new thing" is that owned thing. If the answers to these questions are yes, the proper legal result is clear: we should enforce the in rem property rule and require the "new thing" to be returned to its rightful owner.

If, on the other hand, we find that the original owned thing no longer exists, then there is no "property" to which the "property rule" can be applied; ${ }^{67}$ no res, and hence no rights in rem. ${ }^{68}$ At this point, the only possible remedy is to award the owner compensation for the loss of the

65. For a full discussion of this problem, see Newman, supra note 43 , at 76-84 (synthesizing ideas found in Richard A. Epstein, A Clear View of the Cathedral: The Dominance of Property Rules, 106 YALE L.J. 2091 (1997), and Smith, supra note 37). 66. See id.

67. In Melamed and Calabresi's schema, it would be more correct to say that the owner's entitlement to his destroyed property still exists, but now the only way to enforce the property rule is to impose a penalty on the taker. This penalty is futile in terms of actually protecting the interest underlying the entitlement, but may help to deter non-consensual takings in future. See infra note 122 and accompanying text.

68. See Penner, supra note 39, at 31 ("A right in rem cannot survive the extinction of its res.... If you have wrongfully eaten my cake I can say I have a right in personam against you that you should pay for a cake which I once owned. But I cannot say in the present tense that there is a cake which I still own." (quoting P.B.H. Birks, An Introduction to the Law of Restitution 49-50 (1985))). Or 
original owned thing. Indeed, awarding the owner possession of the "new thing" under these circumstances would itself amount to such compensation by definition, because it would be the substitution of some other thing in the place of the one the owner lost. ${ }^{69}$ Once we recognize that we are making a damages award no matter what we do, it is far from clear that possession of the emergent new thing is the proper one.

If the emergent new thing is found not to share continuous identity with the original owned thing, we then have to ask whether this new thing is itself owned by anyone, and if so, by whom. If the new thing shares continuous identity with some other preexisting owned thing, it should be awarded to the owner of that thing. If not, then we have to decide who should own it as a matter of initial allocation. It remains possible that the owner of the lost original thing may turn out after all to have the best claim to ownership of the new thing. This claim, however, will have to be based on something other than mere ownership of the original thing. ${ }^{70}$

\section{B. The Problem of Identity}

So, under what circumstances does an owned object cease to be what it once was, and become something else instead? Clearly we are treading the confines of deep philosophical sinkholes here, ${ }^{71}$ and it is worth reminding ourselves that while we may need a theory of thingness, it need not be one that would satisfy Heraclitus. The point is not to define identity in the abstract for all purposes and all time, but to decide how, as a practical matter, we should demarcate the identity of a thing as an object of property rights. ${ }^{72}$ This is a concrete legal problem that can be approached

as the school of Roman jurists known as Proculians would put it, "extinctae res vindicari non possunt." See Arnold, supra note 22, at 105.

69. See Lampton's Ex'rs v. Preston's Ex'rs, 24 Ky. (1 J.J. Marsh.) 454, 463 (1829) ("The reason why the material of one which has been changed into a different species by another, is not to be restored to the original owner is, that it can not be returned in kind. It is not the specific thing which belonged to him, and, therefore, is not his, and can not be his ....").

70. The understanding of accession doctrine presented here thus differs from that advanced by Thomas Merrill, who views accession as awarding original allocation of new resources (which may even include increments of value) based on some "prominent connection" between the new resource and some preexisting owned thing. See Merrill, supra note 22, at 460. I think that what Merrill sees as doctrines about making an efficient allocation of newly discovered resources are really doctrines about defining the boundaries of already-owned ones. In other words, we have a name for the prominent connection that animates accession doctrine: it is called identity.

71. For a valiant effort to grapple with the relevant philosophical literature in a patent context, see Kevin Everson Collins, The Reach of Literal Claim Scope into After-Arising Technology: On Thing Construction and the Meaning of Meaning, 41 ConN. L. REv. 493 (2008).

72. Though much has been made of the underlying metaphysical commitments of the rival schools of Roman jurists, it seems likely that this was their approach as well. Jurists of the Proculian School, we are told, were Aristotelians, tending to equate the identity of a thing with its formal cause. See Barry Nicholas, 
like all such problems, by keeping in mind both the purpose of the category and the administrative costs its application will impose.

A key part of what it means to have property rights in rem is that the boundaries of those rights must be readily intelligible to all comers and readily applied by judges and juries. ${ }^{73}$ The identity inquiry must therefore focus largely on social intelligibility-would people naturally tend to conceive of the original thing and the new thing as the "same thing" or not? In order to judge the degree of over- or underinclusiveness of whatever socially intelligible lines we attempt to draw, however, we will have to keep in mind the underlying purpose of property rights: does the "new thing" still have the same universe of potential uses to its owner that the original one did? These two approaches will usually-though not perfectly-tend to complement and reinforce each other, because the way in which human beings conceptually divide the material world into distinct "objects" is closely tied to the usefulness of the objects identified.

\section{Physical Identity}

Any attempt to describe the identity of a physical thing will necessarily be based in large part on concepts describing its physical nature. While it will prove impossible to reduce the problem of identity to a matter of applied physics, it is useful to begin by exploring how far down that road it is possible to go.

\section{Matter, Material, and Form}

When asked to describe a physical object, we inevitably resort to categories of material and form. "Material" is the stuff a thing is made of; "form" is the shape in which the stuff is configured. The potential utility of the object derives from the combination of the two. We describe material in terms of categories (like wood) having certain properties, such as durability, weight, malleability, and combustibility. The properties of a material determine/describe how a thing composed of it will respond when subjected to various forces and brought into contact with various other materials. A material's properties render things made of it potentially useful; for example, as a building component or as fuel. The subset

AN INTRODUction to Roman Law 137-38 (1976); Arnold, supra note 22, at 105. Sabinians, on the other hand, were Stoic materialists, preferring to focus on matter or economic value. See Nicholas, supra, at 137-38; Anna Plisecka, Accessio and Specificatio Reconsidered, 74 TIJDSCHRIFT voOR RECHTSGESCHIEDENIS 45, 47 (2006); see also B.C. Stoop, Non Solet Locatio Dominium Mutare: Some Remarks on Specificatio in Classical Roman Law, 66 Tijdschrift voOR Rechtsceschiedenis 3, 5 (1998) (describing view that jurists' examples originate from schools of philosophy rather than legal practice). J.A.C. Thomas argues (I think persuasively) that these differences have been overemphasized, and that the jurists, while aware of scientific and philosophical thought, were only concerned with "a practical, concrete identity." J.A.C. Thomas, Form and Substance in Roman Law, 19 Current Legal Problems 145, 147-57 (1966).

73. See Smith, supra note 22, at 1760-62. 
of these potential uses that we can realize immediately is bounded by the form in which the material is presently found, which limits our ability to subject it to forces and bring it into contact with other things. Forms, in turn, have their own properties, which can be described in terms of extension in space.

Our application of the categories "material" and "form" is relative and contextual. Any material can potentially be broken down into subparticles having different material properties of their own. Thus, depending on our level of focus, "water" might be described as the material of which a lake is made, or as a particular form in which hydrogen and oxygen atoms can be configured. In a given context, what we call "material" and what we call "form" depends on what physical properties are relevant to our purposes and what kinds of objects we currently possess. ${ }^{74}$ Once we identify the level of material whose properties we are interested in, the subparticles making it up become mere "matter," and are regarded as fungible so long as in the aggregate they give off the material properties we care about. Different specimens of the same material, on the other hand, may or may not be fungible from the perspective of a given would-be user, because such specimens may vary in quality, exhibiting the properties particular to the material in more or less robust form so as to make them more or less useful.

When we engage in productive labor, we tend to call the things we start with materials (e.g., lumber) and give them the form that responds to our specific needs (e.g., barrel hoops). Each specific form renders accessible certain potential uses of the material and precludes others. Sometimes we use labor to transmute one material into another (e.g., wood to charcoal), a process we might also describe as giving another form to the matter of which the original material was composed. Depending on the material, changes in form may or may not be reversible.

While mere matter may be fungible for purposes of utility, it is not for purposes of identity. Imagine two gold cups having exactly the same form and made of exactly the same quality gold. We would describe these cups as "identical," but we would not mean by this that they are one and the "same" cup. They are still two independent objects, two different things. Despite their striking similarity, they are different, the difference being that they are composed of different particles of matter and occupy different locations in space.

At any given moment in time, then, we identify a specific thing as a specific quantity of some material, composed of a specific set of subparticles of matter and having a specific form. Each of those attributes is in constant flux, however, which means that if we are to have any notion of persistent identity at all, it needs to be flexible enough to accommodate the possibility of continuity across at least some degrees of alteration.

74. See Thomas, supra note 72 , at 156 ("Indeed, that which itself in one case is a new species-wine from grapes-is, in another, part of the material for mead."). 


\section{Continuity}

People intuitively understand identity to persist despite incremental changes in either matter or form. While philosophers loved to ponder the conundrum of Theseus's ship, ${ }^{75}$ the Roman jurist Alfenus gave such headscratching short shrift:

[W] here a ship has been so frequently repaired that not even a single plank remains which is not new, she is still considered to be the same ship. And if anyone should think that if its parts are changed, an article would become a different thing, the result would be that, according to this rule, we ourselves would not be the same persons that we were a year ago, because, as the philosophers inform us, the very smallest particles of which we consist are daily detached from our bodies, and others from outside are being substituted for them. Therefore, where the species of anything remains unaltered, the thing itself is considered to be the same. ${ }^{76}$

Alfenus doesn't bother to explain or argue why I should still be considered the same person I was a year ago; he builds his reductio argument concerning the ship on the understanding that everyone would think it absurd not to consider me that way, despite the non-identity of my constituent particles of matter.

We can accept Alfenus's assertion as far as it goes, but there is more that needs to be said. Note that each of the quoted examples contemplates gradual and incremental change. Continuity of form can preserve identity across a series of material changes, but there must also be substantial continuity of matter in the face of each incremental change. Radical discontinuity of matter, on the other hand, does sever identity. If one were to take a ship, completely dismantle it, and then rebuild it from scratch using the same plan but entirely different lumber, we would consider the result a different ship, even though it shared the same species as the original. ${ }^{77}$ Indeed, we have a specific word that describes such a ship and its relationship to the original: replica.

75. See 1 Plutarch, Plutarch's Lives 20 (G.P. Gould ed., Bernadotte Perrin trans., Harvard Univ. Press 1999) (1579) ("The ship wherein Theseus and the youth of Athens returned [from Crete] had thirty oars, and was preserved by the Athenians down even to the time of Demetrius Phalerius, for they took away the old planks as they decayed, putting in new and stronger timber in their place, insomuch that this ship became a standing example among the philosophers, for the logical question of things that grow; one side holding that the ship remained the same, and the other contending that it was not the same.").

76. Dig. 5.1.76 (Alfenus, Digest 6). The term species here can be translated as "outward appearance" - the word being apparently related to specere, or "look at"but it also had (as it does for us) the more abstract meaning of "kind," as in a functional category.

77. An analogous judgment appears to animate 17 U.S.C. $§ 114(\mathrm{~b})$ : 
By the same token, form is capable of undergoing incremental change without destroying a thing's identity. Both the ship and the person are subject to aging, weathering, and modifications-both structural and cosmetic. Such changes do not necessarily make the things any less a ship or a person-or any less the same ship or person. Radical discontinuities in form are another matter. If one were to dismantle the ship and store the lumber in a warehouse-or use it to construct one-no one would regard it as any longer constituting the ship. Even if one were to use the dismantled materials to build something of the same speciesanother ship-if this were done using a different plan, it would not be regarded as the same ship.

Of course, even assuming substantial consensus that "radical discontinuities" like those described above sever identity, flagging such easy cases does not tell us exactly where to draw the line between "incremental change" and radical discontinuity. If over a period of many years I haul my ship onto dry land, embed it in a foundation, and gradually make incremental alterations to render it more suitable as a terrestrial dwelling space, at some point it will probably cease to be a ship and start to be a house even though no single step in the process qualifies as "radical." Focusing on physical continuity alone will not answer these liminal cases, but there will still be many in which the discontinuity is striking enough to generate consensus. Some might be inclined to argue over whether grapes and olives lose their identity when dried or pickled, ${ }^{78}$ but few have disputed that they lose it when transformed into wine or oil. ${ }^{79}$ In the latter examples, the original form has been obliterated entirely. Note too that the legal system will rarely be called upon to decide cases involving extremely long-term gradual change, because such change would have to occur after the thing left its owner's possession to give rise to a transformation scenario. Usually the thing's return would be demanded long before such gradual change had time to occur.

\section{Specification: Identity as Social Intelligibility}

It should already be clear that while a thing's identity is highly dependent on physical properties of material and form, the demarcation of one

The exclusive right of the owner of copyright in a sound recording . . . is limited to the right to duplicate the sound recording in the form of phonorecords or copies that directly or indirectly recapture the actual sounds fixed in the recording[, and does] not extend to the making or duplication of another sound recording that consists entirely of an independent fixation of other sounds, even though such sounds imitate or simulate those in the copyrighted sound recording.

78. Vinnius, drawing from Justinian, held that they did not. See Cornelius van der Merwe, Nova Species, 2 Roman Legal Trad. 96, 104 (2004).

79. See Blackstone, supra note 35 , at $* 404$ (explaining doctrines that making wine, oil, or bread destroys identity of grapes, olives, or wheat "are implicitly copied and adopted by our Bracton, and have since been confirmed by many resolutions of the courts"). 
species from another cannot be reduced to a problem of applied physics. Rather, we define species from "a practical, economic and social point of view," according to which "a thing is identified by its form which connotes the uses and purposes that it serves-a chair, a cup, etc." 80 These practical and social judgments about how best to divide up the material world into intelligible things are embodied in language. The prevalent usage of a distinct word for the result of a particular transformation is therefore probative evidence that the transformation has the sort of practical, economic, and social significance that should be recognized as effecting a change of identity. Language thus provides a useful yardstick against which to test the judgments we might try to make based on sheer physical continuity.

The Romans had a procedural vehicle that made very effective use of this yardstick. Under the Roman formulary system, to bring an in rem action for recovery of property-called vindicatio-you had to identify using a single verbal description both the thing you originally owned and the thing you now wished the defendant to hand over to you. ${ }^{81}$ You were thus required to come up with a set of words satisfying two criteria: 1) it would have enabled a third party examining the thing as it existed in your possession to recognize it as the thing described; 2) it would enable a third party examining the "new thing" in defendant's possession to recognize it as the thing described. If this could not be done, it was an indication that the owned res no longer existed, but had been replaced by a new thing-a nova species. This result later came to be referred to as specificatio. ${ }^{82}$

Given the ingenuity of lawyers and the malleability of language, one might assume that wily plaintiffs who so desired would always be able to find a way to vindicate their transformed property. But what can the owner of a bunch of grapes do after they have been turned into wine? Grapes and wine have entirely different forms; there is no word that encompasses them both without being too abstract (like, say, "comestible") to serve as adequate identification of a particular owned thing. The grape owner would therefore have to resort to identifying the lost property on the level of either material or matter. He might, for example, seek to lay claim to a quantity of "grape juice." Even leaving aside the remaining unbridgeable gap between juice and wine, such an attempt would fail the vindicatio test. While grapes have the potential to become juice, normal usage does not permit a bunch of whole grapes to be properly described in their present state as juice, any more than a block of marble is properly described as a statue, whatever potentiality Michelangelo might see in it. In ordinary parlance, to assert that you possess juice is to assert that you have some quantity of liquid that has already been extracted from the fruit

80. Thomas, supra note 72 , at 156 .

81. See Nicholas, supra note 72 , at $100-02,137-38$.

82. See id. at 136-38; see also Arnold, supra note 22, at 104-09; Plisecka, supra note 72 , at 47 . 
and stored in a form readily accessible to human use. ${ }^{83}$ Other examples from Roman law of transformations resulting in specificatio include: wine and honey mixed to make mead, ${ }^{84}$ malt and corn combined to make beer, ${ }^{85}$ corn ground into flour, ${ }^{86}$ flour baked into bread, ${ }^{87}$ raw metal shaped into useful objects, ${ }^{88}$ wool made into garments, ${ }^{89}$ and trees made into ships or furniture. ${ }^{90}$ Some of these, like the beer and bread, involve radical discontinuities in material. All of them involve radical discontinuities in form.

\section{E. Social Intelligibility $v$. Utility}

The purpose of property rights is to preserve an owner's ability to decide what beneficial use should be made of a particular thing. This suggests that, ideally, our judgment as to when ownership is extinguished would turn on whether the transformation in question has rendered the owned thing incapable of serving the owner's intended uses. If the owner's ability to assign a desired use has been indelibly preempted, then specific enforcement of the property right is moot, and we need concern ourselves only with compensation. If the transformed thing can still serve the owner's intended uses, then we should regard it as the same "thing" notwithstanding the transformation, and return it to her. The vindicatio test can be seen as an application of the in rem principle-rather than inquiring into the subjective desires of the owner, we consult an objective standard of social intelligibility to determine whether the owned thing is still to be regarded as the same thing or not. If so, however, we still need to ask how good a proxy the test is for protecting the underlying interest.

Most of the transformations that result in specificatio will alter the universe of potential uses of the original thing to an extent that makes preemption of the owner's intended use likely. Once the grapes have been made into wine, they can no longer be fed to children, dried into raisins, or placed daintily in one's mouth by a servant whilst one languidly reclines on a lectus. On the other hand, the results of the vindicatio test will be both over- and underinclusive. By overinclusive, in this context, I mean "allowing the owner to enforce her in rem rights even though her intended beneficial uses have been precluded," and underinclusive as "extinguish-

83. As opposed to, say, "stored" in numerous small, roughly spherical vessels that happen to be made of grape skin and flesh. Cf. Lampton's Ex'rs v. Preston's Ex'rs, 24 Ky. (1 J.J. Marsh.) 454, 469 (1829) ("Sugar is but the saccharine matter of the cane, reduced to a separate and concrete state. It may be dissolved into a sweet juice. But it does not therefore belong to the owner of the cane.").

84. See Plisecka, supra note 72 , at 50.

85. See van der Merwe, supra note 78, at 104.

86. See id.

87. See id. at 99.

88. See id.

89. See id.

90. See id. 
ing the owner's in rem rights even though the beneficial use she intended to assign is still possible."

For an example of overinclusiveness, take the dyeing of wool. While making wool into garments did result in specificatio under Roman law, simply dyeing it did not. ${ }^{91}$ This makes intuitive sense: one of the physical attributes of the wool (color) has undergone significant change, but it is not an attribute crucial to the definition of the material, and the form is left unaltered. It is thus not a radical discontinuity of the sort needed to sever identity, and this is reflected in language by the fact that one can still intelligibly describe the resulting thing as wool. Nevertheless, the dyeing may be a deal breaker to the owner's plans; if those plans called for the wool to be dyed a different color, they have been preempted. Allowing such an owner to nevertheless insist on repossession of the same wool (in addition to compensation) is analogous to allowing someone to sue over a harmless trespass. ${ }^{92}$ We do it because the point of the right to exclude is to avoid the need for third parties to make judgments about the owner's actual desired beneficial uses.

There are two important ranges within which the vindicatio is underinclusive. The first arises because the vindicatio test tends to privilege form over material, and there are materials whose potential utility survives unimpaired even when taking on a new form. The main example is metals shaped into useful objects. If my gold ingots get melted down and turned into a gold platter, a strict application of vindicatio would say the platter is a different species. ${ }^{93}$ Yet here (unlike grapes to wine) the specificatio is reversible. The platter can be melted down again, which means that it can still be assigned to any of the uses the owner may have had in mind originally. In cutting off my ownership rights despite this possibility, it appears that the vindicatio test will lead to a bad result in a significant range of cases.

Justinian (following Gaius) ultimately fixed this discrepancy by means of what is called the media sententia, holding that if it was possible to restore the nova species to its prior state then it should be awarded to the original owner. ${ }^{94}$ Note that while this result makes perfect sense from the stand-

91. See id. at 102 .

92. This is not to say that whatever act deprived the owner of the wool was harmless, only that once the wool has been altered in such a way as to no longer serve the owner's purposes, allowing it to remain in the possession of another is harmless.

93. See van der Merwe, supra note 78 , at 99.

94. See J. INST. 2.1.25 (Thomas Cooper trans., 1812); NichOlAs, supra note 72, at 137; Plisecka, supra note 72 , at 57.

[I]f the species or manufactured article can be reduced to its former rude materials, then the owner of such materials is also to be reckoned the owner of the species: but, if the species can not be so reduced, then he, who made it, is understood to be the owner of it; for example; a vessel can easily be reduced to the rude mass of brass, silver, or gold, of which it was made; but wine, oil, or flower can not be converted into grapes, olives, or corn; neither can mulse be separated into wine and honey. But, if 
point of utility, it is somewhat puzzling from that of identity. Doctrinally, the media sententia kicks in after the platter has already been recognized to be a nova species, which means that it is a radically different thing from the ingots, one that has newly come into being, and whose initial ownership is therefore up for grabs. Ordinarily this means that the original owner's in rem rights get extinguished along with the original thing's identity-extinctae res vindicari non possunt-leaving the person who made the nova species (the specificator) to take ownership as a matter of first possession. ${ }^{95}$ The media sententia, however, awards the nova species to the "[owner of] its former rude materials." 96 What does this mean? From the moment the nova species comes into existence, the "former rude materials" no longer belong to the owner of the original thing, so how can such past ownership support the claim to the new thing?

In effect, the media sententia defines a class of materials that are capable of thingness in their own right, without regard to any fixed form, ${ }^{97}$ so that ownership in them can persist regardless of transformation. Once this rule has been announced, we may as well allow owners bringing a vindicatio action to claim a quantity of owned gold without specifying any particular form. ${ }^{98}$ Ultimately, the law came to regard the term specificatio as referring only to those cases in which title would pass to the improver, so that nonreversibility came to be seen as part of the definition of the type of transformation that was required. ${ }^{99}$

a man makes any species, partly with his own, and partly with the materials of another: as, if he should make mulse with his own wine, and another's honey ... . or should make a garment with an intermixture of his own wool with that of another; it is not to be doubted in such cases, but that he, who made the species, is master of it . . . .

J. INST. 2.1.25. For a fascinating discussion and illustration of the reversibility doctrine by an early American court, see Lampton's Ex'rs v. Preston's Ex'rs, 24 Ky. (1 J.J. Marsh.) 454 (1829) (discussing reversibility doctrine). There the dispute was over whether it is possible to restore bricks to the clay they were made from. See id. at 454-55. The trial judge thought that it was, because the bricks could be "dissolved and be made again into soil," while the Court of Appeals disagreed, because "the inherent qualities of the clay, have been transmuted by burning." Id. at 456 , 467 (providing lower courts' decisions). There was no dispute that "unburnt" bricks could be restored to the original clay. See id. at 464 (considering unburnt clay).

95. See Plisecka, supra note 72, at 57 (" [A]ccording to the Proculians the worker owns the product, because it previously belonged to no one: antea nullius fuerat.").

96. J. INsT., supra note 94, at 2.1.25.

97. This was the standard Sabinian position. See Nicholas, supra note 72, at 137-38; Plisecka, supra note 72, at 47. When it came to metals, even Proculians agreed that change in form was usually irrelevant. See Plisecka, supra note 72, at 48.

98. There remain, however, certain metallurgical changes from which even gold cannot return. See Plisecka, supra note 72, at 51 (discussing different results from melting together of lead and silver, which was reversible, as opposed to bronze fused with gold, which was not).

99. See Arnold, supra note 22, at 105 (“[T]o constitute a change of species usually it is held essential that a permanent alteration of the component parts must 
Note that while the reversibility test modifies the vindicatio test in order to better protect owners' interests in use, it still preserves the in rem principle by doing so as a matter of objective definition. The test is not whether the owner would still place value on the material without regard to form, but whether the material has a specific property making it objectively reasonable for the owner to do so, much as the test for nuisance asks whether the expectation of "use and enjoyment" the owner seeks to protect is objectively reasonable. The bright-line rule thus drawn corrects an important range of underinclusion, but still denies the right of repossession to an owner who really did intend to use some non-reversible material for a purpose that is not precluded by its new form.

The other case in which vindicatio is underinclusive is where the (nonreversible) transformation made without the owner's consent was itself the beneficial use the owner had intended to make. What if I had intended to turn my grapes into wine? Why should my rights in rem be terminated just because someone else effected the transformation without my permission? My ultimate desired beneficial use of the grapes was to drink the wine made from them, and that use is still possible if I am allowed to obtain (or as I would prefer to say, "recover") possession of it.

My claim must be rejected, however, because it violates the basic requirement of in rem rights-that the boundaries of the res be defined objectively and categorically so as to be readily understood by third parties without needing to inquire into the subjective desires of property owners. Even though the purpose of the right to exclude is to protect my ability to assign any beneficial use to a thing I wish, ultimately its boundaries are going to be determined, not based on my idiosyncratic intended uses, but based on socially intelligible categorical judgments of utility. As in the case of nuisance, we can explain this in part as a way of avoiding opportunism on the part of owners, who could otherwise always conveniently claim that any value-increasing transformation was exactly what they had intended to do. More fundamental is the issue of information costs. It is as though society has struck a bargain with the property owner that goes: You have a choice. We can define your property rights in terms of your intended uses, in which case you will have to prove your intent and some actual interference with it any time you want to bring an action for trespass. Or we can give you this right to exclude, which will be broader, but whose boundaries will depend not on your subjective intent, but on objectively discernible indicia of identity. In short, property is not "absolutist." It has limits, which are imposed by the objective, socially defined boundaries within which a res retains its identity. Though things are ultimately composed of matter, owners cannot exercise their rights to exclude over the matter as such.

have been made, so that any attempt to change them again to their original form would cause so much damage in proportion to the value as to make it impracticable."). 


\section{F. Accession}

Thus far we have addressed one type of transformation scenariospecificatio-in which the original thing loses its identity by losing its distinctive form and becoming a different thing. Another way in which a thing can lose its identity is through being absorbed into some other preexisting thing, losing its independent thingness and becoming a mere accessory element of something greater, something whose identity remains essentially undisturbed by the absorption. This is known as accessio. ${ }^{100}$ In an accessio case, the originally owned thing may persist in discernible form, but it has been conjoined with some other thing(s) so as to be incorporated into a larger thing. Here two questions arise: 1) Can the original thing be disaggregated and detached as a practical matter? 2) If not, what is the identity (and hence ownership) of the new composite thing-are we looking at "old-thing-to-which-X-has-been-attached," or "X, of which old thing is now a part"? Again, each question is informed by physics, but neither can be reduced to it.

\section{Divisibility}

The function of the reversibility rule from the media sententia was fulfilled in accessio cases by the jurists' recognition of different categories of composite objects, some of which were capable of division back into their original constituent parts. ${ }^{101}$ In such cases, original owners could still get their absorbed property back by vindicatio, if necessary preceded by an actio ad exhibendum forcing its separation from the whole. ${ }^{102}$ Examples of

100. See Nicholas, supra note 72, at 136-38; see also Arnold, supra note 22, at 104-09; Plisecka, supra note 72, at 47. We should note, however, that specificatio and accessio are not different "doctrines" or hermetically sealed categories-just descriptions of ways in which the identity problem can be presented. See Nicholas, supra note 72, at 133-38 ("The criterion applied is essentially one of identity."); Plisecka, supra note 72, at 47 ("[I]n order to determine ownership they considered as foremost the problem of identity, which does not necessarily imply a need to classify a given case into one of the above mentioned categories."). Often one can describe the same situation in such a way as to fit under either rubric. For example, we have already discussed the case of dyed wool as an example of change in the properties of the wool that does not result in specificatio. Another way to describe it would be as a conjoining of the wool and the dye, in which one of the two must accede to the other. The use of the term accession to denote a broadly conceived category of circumstances in which an owner's object of ownership has increased was started by post-Roman commentators and adopted in the French Civil Code. To the Romans, accessio was never such an abstract category. See Nicholas, supra note 72, at 133-34, 134 n.1; Plisecka, supra note 72, at 47.

101. See Plisecka, supra note 72, at 48-49 (discussing three types of corpora: ex distantibus (in which components retain individual character), ex contingentibus (in which components lose their character while conjoined with whole, but can regain it if separated), and uno spiritu (in which components form part of organic whole that cannot regain identity even if separated)).

102. See Dig. 6.1.23.5 (Paulus, On The Edict 21) ("Again, whatever is joined or added to anything else forms part of it through accession, and the owner cannot bring suit to recover it so long as the two articles remain attached; but he can 
this would be recovering your sheep from someone else's flock, ${ }^{103}$ or your bronze arm which had been soldered to someone else's statue. ${ }^{104}$

Sometimes the physical impossibility of dividing two conjoined things is evident, as for example where one's dye has been absorbed into wool, or one's honey dissolved into mead. On the other hand, two things may be regarded as indivisibly joined even though some form of physical division is possible. Where, for example, the bronze arm is welded to the statue, rather than merely soldered to it, the two things are regarded as no longer physically distinct, ${ }^{105}$ and ownership of the arm will not revert to the original owner even if it comes to be removed. ${ }^{106}$ This distinction between soldering and welding makes sense from the standpoint of physical continuity-when things are joined in such a way that there is "mingling of the same material," 107 there is no longer a natural point of division between the two, which means that any act sundering them will necessarily do violence to both, and result in the recovery of the thing only in damaged form. ${ }^{108}$ While this damaging alteration may not be of a degree sufficient to result in specificatio if it had happened to the thing in isolation, here the question is whether the law should require such violence to be

institute proceedings for them to be produced in court, in order that they may be separated, and the suit for recovery be brought ....").

103. See id. ("But with reference to articles which consist of distinct objects, it is evident that the separate parts retain their peculiar character; as for instance, separate slaves and separate sheep; and therefore I can bring suit for the recovery of a flock of sheep, as such, even though your ram may be among them, and you yourself can bring suit to recover your ram."). Thus the flock is an example of a corpus ex distantibus.

104. See id. This may sound like a contrived hypothetical, but apparently statue arms were commonly cast in Roman times as separate pieces and then assembled with the rest of the statue later. See Dorothy Kent Hill, Note on the Piecing of Bronze Statuettes, 51 HesPeria 277, 277-79 (1982). The statue merely soldered together is a corpus ex contingentibus.

105. See DiG. 6.1.23.5 (Paulus, On The Edict 21) (noting that, unlike soldering, welding results in "mingling of the same material" that results in unity). This would be an example of corpus uno spiritu.

106. See id. (" $[\mathrm{I}] \mathrm{f}$ an arm is welded to the statue to which it belongs, it is absorbed by the unity of the greater part, and ... anything which has once become the property of another cannot revert to its former owner, even if it should be broken off.").

107. Id. (describing results of welding).

108. See Bancorp Leasing \& Fin. Corp. v. Stadeli Pump \& Const., Inc., 303 Or. $545,555-56$ (1987) (holding that engine installed in truck did not accede to truck). "In the United States, the severability limitation came to be a rule that "the principle of accession does not apply when the attached articles can be separated and removed from the principal thing without damage to the latter.' Id. at 553 (citation omitted). Whether welding results in accession will of course depend on the nature of the things welded together and the means available for separating them. See McDonald v. Provan (of Scotland St.) Ltd., 1960 S.L.T. 231, 231-32 (Outer House) (assuming that accession could take place when front part of stolen vehicle, including half chassis, engine, and gears, was welded to rear portion of other vehicle, but rejecting this conclusion on facts in part because two were separable). 
done in the name of the owner's rights in rem. To require destruction of the new composite thing, as well as damaging of both the owned thing and the other component, for the sole purpose of restoring the owner to possession of a damaged thing, looks wasteful. ${ }^{109}$ It also looks more likely than not to serve the interests of owners who would assert their rights, not in order to regain the ability to assign use to their originally owned things, but to extract holdup value from owners of new composite things. The refusal to recognize reverted ownership, even if the arm somehow gets detached without legal compulsion, again shows adherence to the in rem principle: once we define objectively the class of composite things regarded as indivisible for purposes of ownership, we do not muddy the waters with individualized findings of actual division.

As with species, divisibility is not solely a matter of physics but of social norms as well. ${ }^{110}$ For example, a house is a corpus ex contingentibus in that we might be able to remove from it particular planks of wood belonging to others, but because the Twelve Tables forbade the removal of materials from an existing building, the owners of the misappropriated planks could not force such separation. ${ }^{11}$ Blackstone provides another example of indivisibility stemming from reasons other than physics: "It hath been held, that if one takes away another's wife or son, and cloaths them, and afterwards the husband or father retakes them back, the garments shall cease to be the property of him who provided them, being now annexed to the person of the child or woman." 112

The most familiar example of indivisibility determined by social norms is the doctrine of fixtures. The question whether a chattel has become annexed to real estate turns in important part on the manner of its physical attachment. But the ultimate test is not whether the chattel is physically removable-if removal were literally impossible, there would be no reason to have a lawsuit over whether it should be allowed. Rather, the relevance of the manner of fixation is that it serves to indicate to third parties whether a thing is intended to be easily removable or not, which in turn signals whether it should be regarded as part of the res. ${ }^{13}$ It is important to understand that the issue here is not whether the actual subjective intent of the affixer was to annex the chattel to the land, an inquiry that would violate the in rem principle. Rather, the question is whether the

109. See L.P.W. van Vliet, Accession of Movables to Land: I, 6 EDIN. L. REv. 67, 69 (2002) ("Once different objects have been joined, adding value to the individual parts, the law should prevent the value thus created from being destroyed by the taking apart of the unity.").

110. See id. at 71 ("In order for accession to take place the bond between the two things need not necessarily be physical.").

111. See W.W. Buckland, A Manual of Roman Private Law 142 (2d ed. 1957). Unlike the case of the welded statue arm, however, the owner would be able to reclaim ownership of the materials if the house came down. See id.

112. Blackstone, supra note 35 , at *404-05.

113. See van Vliet, supra note 109 , at 69 ("The intention of the builder is relevant only as far as it is patent for everyone to see ...."). 
manner of attachment is one that objectively signals such an intent to third parties. ${ }^{14}$ The doctrine of fixtures is ultimately a doctrine of social intelligibility, in which courts consider "physical attachment to the realty, appropriation to the use or purpose of the realty, and common understandings" 115 to decide whether a third party would or would not ordinarily understand something to be part of the land. ${ }^{116}$

\section{Identity}

Assuming we conclude that two things are now indivisibly joined into one, we next have to decide what that one thing is. It is possible that both things have lost their respective prior identities and been merged into a nova species. But often we will rather identify one of the two conjoined objects-the "principal"-as having retained its identity after the merger, and the other-the "accessory" - as having lost it by "acceding" to the principal. There are two main approaches to doing this, which will generally produce similar results. One is the Proculian approach of intelligibility based on species. If you add an arm to a statue, the Proculian will tell you that of course the former accedes to the latter, because the end result is clearly a statue, not "an arm having a large statue-shaped protuberance." Sabinians will reach the same result, only they will say it is because the statue was obviously the larger and more valuable of the two. ${ }^{117}$ Similarly, when it comes to fixtures, once the question of divisibility is resolved there is no serious dispute that the principal thing is the land, of which the chattel has now become a part.

\section{G. Opportunism and Equity}

The responses to the problem of transformation we have outlined thus far are based purely on the logic of in rem property rights, and do not take any notice of the question whether a person who comes to own something as a result of a transformation has acted culpably in taking possession of the original thing. To Roman law, this issue of wrongfulness was irrelevant to the question of title: the party specified by the media sententia (or, where there had been accessio, the owner of the principal object) had title, regardless of whether he had acted in bad faith. ${ }^{18}$ This did not mean that bad faith improvers got away scot free; it just meant that they

114. See id.

115. Merrill, supra note 22, at 467.

116. See van Vliet, supra note 109 , at 71 ("If according to common opinion something is immovable it should be treated as such. Third parties should be able to trust their eyes.").

117. Again, the only area where the two schools seem to disagree as a practical matter has to do with metals. If two masses of raw metal were fused together, the Sabinians would find accessio of the smaller mass to the larger. Since neither mass had definable form however, Proculians would see no rationale for subordinating either to the other. See Plisecka, supra note 72, at 53-54.

118. See Nicholas, supra note 72 , at 135-37. 
were punished by means other than denying them title, namely an action for the delict of theft. ${ }^{19}$ This action resulted in both compensation to the owner and assessment of a penalty for twice the value of the materials, ${ }^{120}$ which would presumably serve to discourage willful takings by means of improvement and provide some substantial compensation for lost subjective value in addition to the market price of the lost goods. On the other hand, wrongful improvers retained the improved property and whatever net benefit it afforded them after these payments had been made. ${ }^{121}$ And why shouldn't they? If we assume that the action for delict reasonably fulfills the important goals of compensation and deterrence, what further purpose is served by denying people the fruits of their labor, or putting those fruits in the control of a party who did not create them? The purpose of property rights is to protect peoples' ability to benefit from their own labor, not to give some people claims over the labor of others. ${ }^{122}$

Should we make this assumption, however? Whether the penalty is adequate to the tasks depends on its size relative to the owner's lost subjective value on the one hand, and the value to be gained through transformative expropriation on the other. To the extent that the penalty fails to destroy all the improver's gains from the wrongful taking, it remains a liability rule, and as such will still run some risk of incentivizing and rewarding opportunism. ${ }^{123}$ In the realm of tangible property, this is an important problem, because opportunistic transformation results in the original owner's loss of particular resources. As we shall see, however, this concern carries far less weight in the realm of copyright.

The common law balked at the idea that one should be divested of ownership through transformative misappropriation, a divergence explained partly by the fact that the common law actions for recovery of possession sound in tort, with questions of restitution addressed to a court of equity. ${ }^{124}$ In any event, the common law modified the original Roman doctrines in two important respects. First, it held that transformation could sever title only where it occurred in good faith ignorance of the

119. See id. at 135.

120. See id.; cf. 35 U.S.C. $\$ 284$ (2006) (providing for treble damages in cases of willful patent infringement).

121. Notice the parallel to patent law, in which the statute awards compensatory damages, plus a multiplying penalty for willfulness, but has no provision requiring disgorgement of profits. See 35 U.S.C. $\$ 284$. Of course, in patent law the usual course would be to enjoin the infringer from any future use of the infringing product, thus denying him all future profits, but that is only because we fail to apply an accession analysis to infringing products in deciding whether to grant injunctions. See generally Newman, supra note 43.

122. Or to express (nearly) the same idea in a different terminology: the purpose of property rights is to incentivize production, not rent-seeking.

123. See Calabresi \& Melamed, supra note 61, at 1092.

124. See R.B. Slater, Accessio, Specificatio and Confusio: Three Skeletons in the Closet, 37 CAN. B. REv. 597, 597-98 (1959). 
rights of the original owner. ${ }^{125}$ This rule provides a more robust disincentive to bad faith appropriation, which is a good thing. But it does so at the cost of diluting the in rem quality of property rights, because the question of title now turns in part on the state of mind of one of the parties. It also means that much rides on the standards for identifying good faith, especially if there turn out to be resources that are easy to appropriate inadvertently, or costly to avoid appropriating knowingly-both concerns that loom large in the realm of copyright. Finally, the common law rule tends to mask an important fact: whenever the improved value of the new thing exceeds the actual subjective value to the original owner of the old thing, plus whatever consequential damages the owner suffered as a result of the deprivation, the owner is getting an unearned windfall. This net excess value of the improved thing is awarded to the original owner in the same manner, and for the same purpose, as a punitive damages award. It serves, not to vindicate any just claims of the owner personally, but as "an undefinable kicker," 126 needed to reinforce society's interest in respect for property rights. Property owners tend not to recognize this. They regard themselves as merely recovering what is rightfully theirs. In fact, they are themselves free riding.

The other respect in which common law diverged from Roman law is that the test for specificatio became much more stringent, holding that ownership remains unimpaired so long as the material remains recognizable, regardless of changes in form. ${ }^{127}$ At common law, the wool made into garments still belongs to the owner of the wool, despite the fact that it has been irreversibly cut, dyed, and sown in such a way as to indelibly preempt its owner's ability to assign any other use. ${ }^{128}$ Specificatio is still possible, but only in cases where the material is irreversibly transmuted into a different one. ${ }^{129}$ This expansion of the owner's in rem rights renders them far more

125. See, e.g., Lampton's Ex'rs v. Preston's Ex'rs, 24 Ky. (1 J.J. Marsh.) 454, 459 (1829) (" $[\mathrm{N}]$ o trespasser, who takes property of another wantonly and without the owner's consent, can ever acquire a right to it by any 'accession' or 'specification,' whatsoever."); see also Newman, supra note 43, at 90-93.

126. Calabresi \& Melamed, supra note 61 , at 1126.

127. See, e.g., Betts \& Church v. Lee, 5 Johns. 348 (N.Y. Sup. Ct. 1810) (holding title to shingles remained in owner of original timber). "[W] hatever alteration of form any property has undergone, the owner may seize it, in its new shape, if he can prove the identity of the original materials ...." Id. at 350; see Lampton's Ex'rs, 24 Ky. ( 1 J.J. Marsh.) at 460 ("It seems to have been an established doctrine of the common law, as early as the year books, that no change of mere form could divest the right of the owner of the material, as leather made into shoes, cloth into a coat, timber into a plank, blocks or shingles; in all which cases the material is not altered in its qualities or kind, and can be easily identified.").

128. See Lampton's Ex'rs, 24 Ky. (1 J.J. Marsh) at 458-60. We should note, however, that some common law courts have continued to take a more Roman view of the matter. See M'Laren Sons \& Co. v. Mann, Byars \& Co., 51 Sc. L.R. 57 (Sheriff Ct. 1935) (determining clothing company destroyed separate existence of cloth and created new species by converting cloth into workmen's garments).

129. See Lampton's Ex'rs, 24 Ky. (1 J.J. Marsh.) at 467-70 (holding that clay had been transmuted into different material due to being baked into brick). 
overinclusive than they were under Roman law, and makes it harder to justify the application of specificatio in the area where it remains. What purpose is served by holding that ownership of a tree survives its transformation into barrel hoops, but ownership of grapes does not survive their transformation into wine? In either case, the owner's ability to assign use to the original thing has been irrevocably preempted. The only rationale for this remaining distinction is that property in a quantity of a given material is marginally more intelligible than property in a quantity of sheer matter, because material is more readily recognizable, and a given specimen of material might have particular qualities rendering it non-fungible from an owner's perspective. Sensing the lack of a robust rationale for this remaining barrier, some common law courts went ruthlessly Sabinian, pursuing recovery of the original owner's property even through chemical transformations. ${ }^{130}$ In this respect, the common law approach to transformation scenarios might justly be called absolutist.

This great expansion of the range of transformation within which a res would be viewed as having continuous identity led to an expansion of the situations in which people who effected transformations without properly securing property rights would find the fruits of their labor forfeited. $\mathrm{Ab}$ sent a radical transformation of the kind still recognized as specificatio, even improvers who acted in good faith ignorance of the owner's rights would be required to turn the improved thing over, and would have no claim to compensation for the value imparted by their labor. ${ }^{131}$ This led to expanded opportunities for holdup by property owners, and ultimately to a counterbalancing move in the name of equity, exemplified by Justice Cooley's opinion in Wetherbee $v$. Green: ${ }^{132}$

No test which satisfies the reason of the law can be applied in the adjustment of questions of title to chattels by accession, unless it keeps in view the circumstance of relative values. When we bear in mind the fact that what the law aims at is the accomplishment of substantial equity, we shall readily perceive that the fact of the value of the materials having been increased a hundred-fold, is of more importance in the adjustment than any chemical change or mechanical transformation, which, however radical, neither is ex-

130. See, e.g., Silsbury v. McCoon, 3 N.Y. 379, 392-93 (1850) (allowing owner of interest in wrongfully taken corn to seize whisky made from it).

There is no satisfactory reason why the wrongful conversion of the original materials into an article of a different name or a different species should work a transfer of the title from the true owner to the trespasser, provided the real identity of the thing can be traced by evidence.

$I d$. at 390. But see Isle Royale Mining Co. v. Hertin, 37 Mich. 332, 336 (1877) (Cooley, C.J.) (noting that "other authorities refuse to go so far").

131. See Arnold, supra note 22, at 117 (stating that courts have denied such recovery "without exception"). "If the title remains in the owner, he may seize the article in the improved condition. If the thing is his, on what theory can the owner be made liable in damages for taking that which is his own?" Id.

132. 22 Mich. 311 (1871). 
pensive to the party making it, nor adds materially to the value. There may be complete changes with so little improvement in value, that there could be no hardship in giving the owner of the original materials the improved article; but in the present case, where the defendant's labor-if he shall succeed in sustaining his offer of testimony-will appear to have given the timber in its present condition nearly all its value, all the grounds of equity exist which influence the courts in recognizing a change of title under any circumstances. ${ }^{133}$

Justice Cooley's equitable doctrine appears to apply two criteria in deciding when to decline enforcement of the owner's in rem rights. First, there must be a vast disparity in market value between the taken thing and the improved thing. It need not be literally "a hundred-fold,"134 but it must be large enough that we are willing to say the value of the labor has "swallowed up and rendered insignificant by the value of the original materials." 135 The other part is-still-the presence of some irreversible physical transformation effected by productive labor of the defendant. ${ }^{136}$ Only now the issue of irreversibility serves, not to define a restricted class of materials capable of being owned regardless of form-because all of them can-but rather as a proxy for the extent to which we should regard the thing's present value as owing to the improver's input. If we are making an equitable judgment that the owner's interest is dominated by that of the improver, we would not want to reward someone who merely misappropriated property and held it during a period of time when it increased in value for reasons having nothing to do with the holder's actions. ${ }^{137}$ Conversely, to the extent the original material remains discernibly tracea-

133. Id. at 320-21 (Cooley, J.) (declining to allow plaintiff landowner to recover possession of barrel hoops created by good-faith improver from timber cut on plaintiff's land).

134. The value ratio of the trees to hoops in Wetherbee was actually only one to twenty-eight. See Isle Royale Mining Co., 37 Mich. at 337 (stating that in Wetherbee, trees were worth $\$ 25$, hoops $\$ 700$ ).

135. Wetherbee, 22 Mich. at 320; see Epstein, supra note 65, at 2102 ("[T]he appropriate solution [to the analogous problem in nuisance cases] is to allow injunctive relief when the relative balance of convenience is anything close to equal, but to deny it (in its entirety if necessary) when the balance of convenience runs strongly in favor of the defendant."); Newman, supra note 43, at 99-101 (discussing "Epstein's Rule"); cf. Isle Royale Mining Co., 37 Mich. at 334, 338 (providing example six years after Wetherbee where Justice Cooley rejects similar accession claim in which value of cut timber had been increased only ten times).

136. See Isle Royale Mining Co., 37 Mich. at 336 (Cooley, C.J.) ("[W]here the appropriation of the property of another was accidental or through mistake of fact, and labor has in good faith been expended upon it which destroys its identity, or converts it into something substantially different, and the value of the original article is insignificant as compared with the value of the new product, the title of the property in its converted form must be held to pass to the person by whose labor in good faith the change has been wrought ...." (emphasis added)).

137. On the difficulty-but ultimate justifiability-of distinguishing the two, see Newman, supra note 43 , at 75 . 
ble into the new form, we may want to raise the relative value bar higher. ${ }^{138}$

Justice Cooley's opinion can be seen as completing a transformation of accession doctrine. Originally, the owner's in rem rights had been limited to a specific thing, bounded by a restrictive form-based definition. When a transformation occurred, title to the resulting thing turned purely on whether it stood within this definition or outside it. Now, the owner's in rem rights are assumed to survive all but the most extreme transformations, and termination of title becomes the province of an equitable doctrine focused on identifying rare circumstances in which it would be unfair not to give the transforming party a break.

\section{COPYRIGHT}

\section{A. Property v. Copyright}

We can tell a story about copyright whose broad strokes sound very similar to the one just told about accession doctrine: At first, works of authorship had strictly defined boundaries, so that most significant transformations fell outside the scope of the author's right. ${ }^{139}$ This scope was expanded in response to concerns about misappropriation of value. A key facet of this expansion was increased willingness to treat material substrata of the work as capable of sustaining claims of ownership, even if found in a very different form. ${ }^{140}$ Eventually we reached the point where most transformations are assumed to infringe, and most of the work of limiting the scope of the owner's rights is done, not by intrinsic definitions of the object of ownership, but by an equitable doctrine focused on exempting certain infringers after the fact.

In the realm of tangible property, such equitable determinations need be made only rarely, and accession doctrine does little to undermine the overall in rem character of property rights. ${ }^{141}$ In copyright, transformation problems are central to a large portion of copyright infringement cases-all those in which a work is alleged to infringe though it is not a complete, verbatim copy of the original owned work. The result of resolving these transformation problems on an ad hoc basis is that outcomes are

138. See Isle Royale Mining Co., 37 Mich. at 337 (Cooley, C.J.) ("But where the identity of the original article is susceptible of being traced, the idea of a change in the property is never admitted, unless the value of that which has been expended upon it is sufficiently great, as compared with the original value, to render the injustice of permitting its appropriation by the original owner so gross and palpable as to be apparent at the first blush.").

139. See Paul Goldstein, Derivative Rights and Derivative Works in Copyright, $30 \mathrm{~J}$. CoPYRIGHT SoC'Y U.S.A. 209, 211-13 (1983) (explaining that copyright was initially construed narrowly, such that translations and abridgments did not infringe).

140. See generally Castle Rock Entm't, Inc. v. Carol Publ'g Group, Inc., 150 F.3d 132 (2d Cir. 1998). For a discussion of Castle Rock Entertainment, see infra notes 170-74 and accompanying text.

141. See Newman, supra note 43 , at $92-93$. 
intolerably difficult to predict with confidence, and freedom of expression is curtailed by default as people accede to copyright owners' demands rather than risk liability. ${ }^{142}$ The blame for this has been laid at the door of copyright's "propertarian" nature. Given that the story told above has property arriving at much the same place as copyright, one might conclude that the charge is just after all. The very fact that transformation is so central to copyright law, however, tells us that allowing it to be governed primarily by ad hoc reasoning constitutes a basic failure to implement the propertarian strategy of rights in rem. Furthermore, the expansion of the scope of the owned res that necessitates such frequent resort to ad hoc reasoning in copyright lacks the justification underlying the parallel expansion in post-Roman property law. True propertarian reasoning is not a facile assertion of one-size-fits-all ownership, but a nuanced application of certain basic principles to circumstances on the ground. ${ }^{143}$

Tangible property rights protect the human interest in assigning uses to particular tangible things. When a transformation deprives an original owner of title, it means the loss of an originally owned thing. The fear that allowing a wide range of transformations to terminate title will encourage costly opportunism, therefore, has serious weight. Acts of copyright infringement, however, do not deprive copyright owners of their exclusive control over any tangible thing. The interest protected by copyright law is rather an author's interest in using a work of authorship as a basis for exchange of value. If a putatively infringing work is found not to be a copy of the work of authorship (or a derivative work thereof), then the copyright owner is deprived of nothing, for it means that no part of the exchange value to which the owner is entitled has been diverted. Whereas successful transformation of a tangible thing ensures that the original owner's loss will never be perfectly repaired, successful transformation of a work of authorship prevents any loss from occurring. There is thus no need to expand the scope of in rem rights simply in order to avoid rewarding opportunism; in this arena, genuinely transformative "opportunism" is an unalloyed good.

\section{B. Outline of an In Rem Approach to Copyright}

To successfully implement the in rem strategy in the realm of copyright, we have to, first, provide clear boundaries to the work of authorship and its derivative works, and second, define the categories of actions affecting such works to which we will apply a strict right to exclude (i.e., decide what should constitute trespass). In drawing these lines, we hope

142. See generally Gibson, supra note 17.

143. See Newman, supra note 43; see also Epstein, supra note 35, at 806 (property rights involve "delicate tradeoff and accommodation" in light of extant institutions, individuals, and circumstances, to determine "what kinds of tradeoffs are sustainable and what kinds are not"). 
to achieve the following goals: 1) provide lines that can be readily understood by all duty-holders without any need to investigate owner preferences, 2) effectively protect authors' interests, and 3) avoid placing overinclusive burdens on the freedom of duty-holders that are not justified by a high likelihood of harm and high information costs in distinguishing interference from non-interference.

If it is possible to draw a set of lines having these characteristics, the question arises whether we will need a fair use doctrine at all. Broadly speaking, there are two reasons why we might want to exempt from liability an action nominally falling within the scope of an owner's right to exclude. The first is that the action does not really conflict with the interests the right is designed to protect. We can call these "non-conflicting uses." When the right to exclude is properly calibrated, the area of its overinclusiveness (i.e., the number of non-conflicting uses it encompasses) is narrow enough that we feel comfortable enforcing it categorically, because the harm from overinclusion is less than the cost of making finer grained judgments. Thus, we are willing to enjoin trespasses without proof of actual interference with the owner's use of the property. If, on the other hand, the area of overinclusion encompasses so many activities-and activities of enough importance-that we find it necessary to make case-by-case judgments as to whether facial infringements should be treated as real infringements, this should tell us that the right to exclude is not fulfilling its bright-line function and really ought to be recalibrated.

The second reason for exempting a facial violation of the right to exclude is that, even though it does impact the interests we generally intend the right to protect, the circumstances are such that those interests are trumped by other countervailing principles. We can call these "privileged uses," of which the primary example in tangible property would be necessity. ${ }^{144}$ So long as privileged uses are restricted to well-defined categories, they do not undermine the bright-line function of the right to exclude and thereby impair the benefits of in rem property rights.

Fair use doctrine is muddled in large part because we are using it to identify both non-conflicting uses and privileged uses, and, as a result, we wind up blurring the distinction between the two. ${ }^{145}$ Indeed, we wind up unable to identify either type of use in isolation, and are left instead with a series of case-by-case judgments in which both privilege (i.e., identification of works whose value we are unwilling to suppress by enforcing property rights) and lack of conflict (i.e., "transformative nature" of the infringing work and effect on the owner's market) are matters of degree, and exemptions are granted on a sliding scale that weighs the two against each

144. For a further discussion, see supra note 56 and accompanying text.

145. See Pamela Samuelson, Unbundling Fair Uses, 77 Fordham L. Rev. 2537, 2557 (2009) (pointing out desirability of distinguishing between transformative uses and "iterative copying for orthogonal speech-related purposes"). 
other. ${ }^{146}$ Not only does this mean that questions of copyright infringement cannot be resolved without frank resort to external reasoning, but conflation of the two kinds of exemption degrades the clarity of this reasoning. The result is utter contravention of the in rem principle-copyright is enforceable against everyone, but no one can predict with confidence where its boundaries will be determined to lie.

My effort below to reconstruct copyright doctrine is focused primarily on trying to provide a clearer account of what sorts of uses ought to be regarded as non-conflicting, and how we might calibrate the right to exclude so that its (inevitable) overreach into the area of non-conflicting use stays within a range that is justified and tolerable. This means trying to give the terms work of authorship and derivative work well-defined intrinsic limits that can do independently most of the work presently being done by the notion of transformative use. If this were done properly, it would mean that any excluded use of an object properly termed a "copy" (or derivative work) of a copyrighted work would be categorically infringing, unless it qualified as a privileged use. This would mean, in turn, that fair use doctrine would have no need to talk about transformative use, and would instead become exclusively a doctrine about identifying privileged uses,

In my view, what copyright doctrine presently calls transformative use ought properly to be called "use of objects that have discernible sensory or expressive continuity with copies of the work, but that are not properly identified as copies or derivative works." Or, more succinctly, "non-use." The relationship between actual copies and such objects is analogous to that between an owned thing and the new thing that results after an occurrence of specificatio or accessio, and, as in those cases, it is recognized by applying objective standards based on social intelligibility and utility. The touchstone of the determination can be stated: A copy serves to facilitate beneficial use of a work as designed by its author; a non-copy does not. To "prepare a derivative work," 147 on the other hand, is to prepare a copy of a work that has undergone some transformation with respect to the original form in which its author fixed it, but that still remains within the range of continuous identity and utility qualifying it as a copy of the work.

Many of the uses currently defended by champions of transformative fair use will qualify as non-use under my analysis. This means that they do not constitute uses of "the copyrighted work," and hence do not facially violate any of the exclusive rights in section 106, making resort to fair use

146. See Suntrust Bank v. Houghton Mifflin Co., 136 F. Supp. 2d 1357, 1372 (N.D. Ga. 2001) (describing Supreme Court as having adopted "sliding scale approach" under which " the more transformative the new work, the less will be the significance of other factors, like commercialism, that may weigh against a finding of fair use'" (quoting Campbell v. Acuff-Rose Music, Inc., 510 U.S. 569, 579 (1994))), rev'd, 268 F.3d 1257 (11th Cir.). do so).

147. See 17 U.S.C. $\$ 106(2)$ (2006) (giving copyright owner exclusive right to 
analysis unnecessary. On the other hand, there will be some uses currently asserted by some to be transformative that my analysis will conclude to be uses of copies. ${ }^{148}$ This does not necessarily lead to the conclusion that these uses should be excluded, for the possibility remains that they should be privileged uses. The question as to what categories of use should be defined as privileged is beyond the scope of this article. I think discussion of this question might be improved, however, if it were disaggregated from the question of transformative use.

\section{Works of Authorship and Their Uses}

The Copyright Act does not attempt to define the nature of the crucial species at the heart of all copyright doctrine-the work of authorship. ${ }^{149}$ This omission, while understandable given the difficulty of the task, is a large part of the reason why the internal approach to copyright doctrine is unable to achieve the clarity required by a well-functioning system of in rem rights. Some understanding of the nature and utility of works of authorship is necessary if we are to usefully identify the author's interest in them and find a properly calibrated way to protect it.

I propose the following definition: A work of authorship is a planned sensory experience, designed by its author to give rise to an expressive experience in the mind of one or more intended audiences. The sensory experience consists of a specific selection and arrangement (spatial and/or temporal) of sensory inputs that is perceived by the person "consuming" the work. The expressive experience consists of a specific set (and for some works, a specific sequence) of intellectual responses that the sensory experience is designed to arouse in the mind of the audience. ${ }^{150}$ An intended audience consists of people equipped with the minimum sensory and conceptual apparatus (e.g., language) needed to translate the sensory experience in to the expressive experience designed by the author. The purpose of the

148. See infra Part IV.J.

149. See H.R. REP. No. 94-1476, at 51-52 (1976) [hereinafter House RePORT] ("The phrase 'original works of authorship' ... is purposely left undefined ...."). No specific purpose for this omission is stated in the report, though one gathers that it stems in part from a desire to avoid taking any position on the precise scope of copyrightable subject matter:

The bill does not intend either to freeze the scope of copyrightable subject matter at the present stage of communications technology or to allow unlimited expansion into areas completely outside the present congressional intent. Section 102 implies neither that that subject matter is unlimited nor that new forms of expression within that general area of subject matter would necessarily be unprotected. Id. at 51 .

150. See id. at 56 ("Copyright ... pertains to the literary musical, graphic, or artistic form in which the author expressed intellectual concepts."). I use the term expressive experience to denote the total cumulative effect of the "intellectual concepts" expressed in a work on the person who consumes it. We should note that despite its discursive flavor, intellectual concepts here must include such things as the inarticulable effects produced in the mind by things like musical chords and non-representational images. 
expressive experience, in turn, is to give rise to various expressive effects on the audience. It is because we assign utility to these effects that we value works of authorship and have erected a legal institution intended to foster their creation.

We can divide these effects into two broad categories. First are aesthetic effects, by which I mean the various types of pleasure (or displeasure) one derives from contemplation of an expressive experience as an end in itself. ${ }^{151}$ Second are epistemic effects in which I include instruction, edification, and any other process through which one's intellect comes to incorporate some meaning derived from (or, if you prefer, constructed around) the expressive experience. Here it is important to distinguish between value arising from the content of the information itself (such as facts), and that arising from the form in which the information is presented to the mind so as to alter (thus endowing with various qualities and degrees of utility) the manner in which the user's mind comes to comprehend, assimilate, react to, or remember it. Only the latter is a proper subject of copyright protection. These two categories of expressive effects are not hermetically sealed-pleasure is informed by meaning and vice versa. One may, for example, take pleasure both in a book or painting's style, and in one's approbation of its perceived meaning.

Some people are likely to regard with extreme skepticism any attempt to speak of specific "expressive experiences" designed by authors, let alone of ultimate "expressive effects" authors seek to induce in their audiences. One can argue over whether authors need or ought to have any such precise intent with regard to the effects their works will have. Even assuming such intent exists, one can question the extent to which it is likely to be determinative of, or even relevant to, the effects a work actually has on its audience, each member of which will interpret the work through the lens of his own personality and experience. There is only one way in which copyright law can absolutely avoid wading into this quagmire, however, and that is to limit itself to policing verbatim reproductions. If we are to entertain the possibility that a work can be infringed by a copy that departs, even trivially, from the original, we have no choice but to confront the problem of identifying the character of a work on some level of abstraction that permits us to judge which departures are trivial and which are not. Once we undertake this, we will inevitably find ourselves talking in one way or another about the effects the work has (or would be expected to have, or was intended by its author to have) on an audience. ${ }^{152}$

151. See Baker v. Selden, 101 U.S. 99, 103-04 (1879) ("Of these it may be said, that their form is their essence, and their object, the production of pleasure in their contemplation.").

152. See, e.g., Arnstein v. Porter, 154 F.2d 464, 473 (2d Cir. 1946) ("The question, therefore, is whether defendant took from plaintiff's works so much of what is pleasing to the ears of lay listeners, who comprise the audience for whom such popular music is composed, that defendant wrongfully appropriated something which belongs to the plaintiff.") 
Rather than attempting to import any theory of artistic criticism into copyright law, I mean to construct a very simple model of artistic intent that is compatible with the needs of copyright as a system of property rights.

What I term the expressive experience of a work does not encompass all the ultimate thoughts, associations, and emotions that the work triggers in the mind of each given user, or the indefinite number of interpretations that can be derived from (or constructed around) it. All these things are among, what I call, the work's expressive effects, and they will vary widely among audiences and individual audience members. There is a sense in which no two people can ever read the same book, because no two people will bring the same intellectual and emotive schema to bear in experiencing its contents. If we are going to take the notion of a copyrighted work seriously, however, we must also posit that there is a meaningful sense in which two people can read the same book, even though we know they will read it somewhat differently. ${ }^{153}$

In referring to the expressive experience of a work, I mean, foremost, to denote some basic stratum of intelligibility, consisting of the minimum expressive content that any qualified member of an intended audience would be expected to recognize as present upon processing the sensory experience. This stratum forms the basis for all aesthetic reaction to the work, all interpretation or construction of whatever additional layers of meaning we may attach to it. You may read The Wizard of $O z$ as a whimsical children's tale or as an allegory about late nineteenth-century monetary policy; ${ }^{154}$ you may find it enthralling or tedious, edifying or pernicious. But to read it at all means at minimum to experience an intelligible narrative describing a young girl who has a specific series of adventures in a magical land. ${ }^{155}$ Furthermore, it means to apprehend this content as conveyed through a specific set of literary devices, which inform both what the reader understands the content to be and what expressive effects it will have on him. This serial processing of information through engagement

153. Cf. Don Herzog, As Many as Six Impossible Things Before Breakfast, 75 CAL. L. REv. 609, 629 (1987) (noting some "obvious conundrums" facing any radical skepticism about interpretation). Herzog notes:

I have a distressingly large library, one which keeps growing. I lug books from my apartment to my office, from one library to another, from New York to Michigan. I pile them up and occasionally face the incredibly dreary task of loading them into boxes. Why do I bother? Why don't I just have one text, say a large piece of paper with the tantalizing word 'TEXT' inscribed in the middle in Gothic lettering? I could then interpret it any way I wanted: I could read Henry James into it, or out of it, or Id.

Joyce, or Simmel, or ....

154. See Hugh Rockoff, The "Wizard of $\mathrm{Oz}$ " as a Monetary Allegory, $98 \mathrm{~J}$. PoL. ECON. 739 (1990) (suggesting, inter alia, that the Wicked Witch of the East was Grover Cleveland, politically crushed by the cyclonic force of the free silver movement).

155. When a work is non-representational, it becomes more difficult to provide any description of the expressive experience that differs materially from a detailed description of the sensory experience. 
with a specific sequence of intelligible forms, along with its immediate results on the level of conscious apprehension, is the expressive experience of the work. If we are to take the notion of authorship around which all of copyright law revolves seriously, we must posit at minimum that authors can and do design such experiences and encode them in fixed sensory data, with a reasonable expectation that qualified audience members exposed to the sensory data will apprehend them-on at least one level-in a predictable and similar way.

We must also posit that the purpose of encoding and apprehending expressive experiences is to create and enjoy the effects they give rise to, and that in designing such experiences, authors have at least some intent with regard to the nature and qualities of the effects they hope to create. If they do not, it makes little sense to speak of rewarding them for the value they create, or incentivizing them to create it. ${ }^{156}$ The specificity with which it is possible to describe this intent will vary widely between different artists, media, and types of work. Many works are intended to be ambiguous or multivalent in significant respects; all are inevitably so because of the idiosyncracies of audiences and audience members. Nevertheless, while it is impossible to fully specify all the ultimate expressive effects a work will have on a given audience or individual, it is possible to make judgments about certain ranges of effects that a work is objectively likely to have on audiences sharing given qualifications, and in turn about the manner in which various aspects of the expressive experience combine to create them. We assume that authors intend to create these effects, and that consumers' desire to enjoy them is what gives exchange value to the authors' exclusive rights to control access to the work.

To create a work of authorship, then, is to design an expressive experience intended to have utility to others. To make beneficial use of a work of authorship is to recreate the expressive experience conveyed by the work in one's mind in order to enjoy its expressive effects. ${ }^{157}$ For this to happen, the work first has to be instantiated in some object such that its contents can be communicated to the user's intellect via sense perception, whether by directly perceiving the copy or by perceiving a display or performance somehow based on it. To perceive the work in this way is to make beneficial use of both the copy and the work. Not every beneficial use of a copy, however, is also a beneficial use of the work embodied in it. This is because it is possible to derive a benefit from a copy of a work that does not depend on deriving the benefits afforded by the expressive expe-

156. See Shyamkrishna Balganesh, Foreseeability and Copyright Incentives, 122 HaRv. L. REv. 1569, 1601 (2009) (“[L]ow-probability outcomes are thought incapable of playing a significant role in inducing ex ante behavior ....").

157. To the extent that computer programs are proper subjects of copyright law, it is because their source code is intelligible to human beings who can (and do) read it, deriving expressive benefits from doing so. Those who only run a computer application on their machines is not making beneficial use of the program qua work of authorship, they are making beneficial use of it qua functional component of their computers. 
rience of the work. A trivial example would be the use of a book as a paperweight or doorstop. Here, even though the copy is being used, it is being used not qua copy but only qua physical object. More importantly, however, it is possible to derive second-order benefits from displaying a copy of a work to others for various communicative purposes that $d o$ depend on the copy's nature as such, but which do not necessarily involve causing those others to derive the expressive benefits the work was designed to convey. For example, I may display a work to someone, not to entertain or edify them, nor to impart the information conceptually contained in the work itself, but to communicate the second-order information that I am the kind of person who likes that kind of work.

Beneficial use of a work of authorship is never consumptive in itself. The recreation in my mind of the expressive experience of a work does not of its own force consume opportunities for others to do the same. This is the sense in which we say that works of authorship are nonrival. On the other hand, such beneficial use may well involve consumptive use of a copy of the work (e.g., reading a book), which will consume opportunities for others to make use of the work by means of that copy. To protect people's ability to make beneficial use of a work of authorship, all we need to do is to subject copies of the work to the same property rights as all other useful objects. To the extent that authors labor for the purpose of making beneficial use of their own creations, ${ }^{158}$ they have no need of copyright protection.

\section{Property Rights and Value}

According to the account given in Part II above, a tangible property owner's right to exclude is not designed primarily as a tool for allocating value, but rather as one for rendering possible the realization of value by protecting the owner's chosen beneficial uses from interference. This is not to say that rights to exclude have no allocational consequences. Obviously, they do-as a practical matter, enforcement of the right to exclude will have the result of allocating all value dependent on possessory uses of an owned thing to the thing's owner. This owner will be in a unique position to realize such value either directly, by engaging in the valued uses, or indirectly, by using the exclusive rights to those uses as a basis for exchange. The allocation of rights to exclude therefore results in the allocation of value. The scope of the right to exclude, however, is not designed to capture all value arising from the owned thing, but only to protect an owner's beneficial uses from preemption by unauthorized possessory uses. Any value arising proximately from the owned thing that can be enjoyed without possessory use or actionable nuisance (e.g., the pleasure of con-

158. Many works-and perhaps most of the most valuable ones-are created for this motive alone. Copyright may help such authors obtain the wherewithal to create such works, but it does not necessarily provide any otherwise lacking incentive to do so. See Rebecca Tushnet, Economies of Desire: Fair Use and Marketplace Assumptions, 51 WM. \& MARY L. Rev. 513 (2009). 
templating a skyscraper built on my property) is not allocated to its owner, but rather to the owners of whatever other things one has to make possessory use of in order to realize that value (e.g., the sidewalk or other vantage points from which the skyscraper can be viewed). ${ }^{159}$

The key distinction between copyright and traditional property is that because copyright seeks specifically to protect the author's use of the work as a basis for exchange of value, questions as to the proper scope of copyright cannot be cleanly divorced from questions as to the proper allocation of value. This difficulty is what gives the expansionist impulse much of its force. If the assumed goal is to reward authors for their creative labor (whether to incentivize them or because we believe it just to do so), then the question as to whether a given increment of value should be allocated to an author tends to reduce to-Is this value a result of the author's creative labor? This makes it easy to conclude that any value of which the author's creativity is a but-for cause should be allocated to the author, unless we can point to strong countervailing reasons why not. Such expansionist reasoning, sometimes derided as "if value, then right," 160 has been attributed to (blamed on) property theory, even though neither traditional property doctrine nor natural law theory says anything of the kind. The Lockean argument is not: "You should own anything that is rendered more valuable to anyone as a proximate result of your productive labor." Rather, it is: "You should be allowed to own specific things that you labor on, so that you will be able to enjoy the beneficial uses of those things that your labor makes possible." ${ }^{161}$ The key to a propertarian, non-expansionist copyright, then, is to reemphasize that ownership rights are granted, not in some share of the value arising from authorial labor, but in the

159. See Penner, supra note 49 , at 818 ("It has never been the case that every casual extraction of the value of someone else's property is illegal, for example my appreciation of my neighbor's garden by looking over the fence. Value per se has never been the limit on the right of exclusive use, for it depends on the duty of non-interference, which is rarely comprehensive.").

160. See Mark A. Lemley, Ex Ante Versus Ex Post Justifications for Intellectual Property, 71 U. CHI. L. Rev. 129, 131 n.7 (2004) (collecting examples). Rebecca Tushnet and others have also criticized me for taking what they (not unreasonably) perceived to be the same position. See Tushnet, supra note 158, at 519 n.14 (commenting on Alex Kozinski \& Christopher Newman, What's So Fair About Fair Use?, 46 J. Copyricht Soc'y U.S.A. 513, 524 (1999)). The point we were trying to make there, however, was not that all parodies should necessarily be held to fall within the scope of an author's rights, but that to the extent a parody would otherwise do so, its parodic nature was not a reason to deny the author any form of remuneration, providing that such remuneration was divorced from censorial control. As the remainder of this article should make clear, I at least (I cannot speak for my co-author) do not think the parody at issue in Dr. Seuss Enters., L.P. v. Penguin Books USA, Inc., 109 F.3d 1394 (9th Cir. 1997), should have been regarded as substantially similar at all.

161. See Simmons, supra note 45 , at 276 ("We can make property only in what is actually labored on and continues to be used in our projects ...."). 
specific thing to whose creation the author directs her labor: the work of authorship. ${ }^{162}$

\section{E. The Identity of the Work of Authorship}

As we saw in Part III above, the effective scope of an owner's property rights varies greatly depending on whether a thing's identity is thought to depend on its form, or whether it can persist based on continuity of material alone. This article takes the position that in effect, copyright law has gone too far down the road of protecting "material." The purpose of defining "work of authorship" in terms of a specific expressive experience is to place the issue of coherent, intelligible, and deliberately chosen form at the center of our understanding of what gives a work its identity as an object of ownership. This is in contrast to a tendency of some courts to treat the work as a mass of "protected expression," and to treat any use of more than a de minimis quantity of this material as a use of the work.

In one sense, my contention is entirely uncontroversial. It is fairly standard black letter law that copyright "pertains to the literary, musical, graphic, or artistic form in which the author expressed intellectual concepts." 163 The problem, again, is that form is a relative term, in that it can be identified at various levels of organization. In copyright discourse, the term form is associated with that of "expression," and each is used in counter-distinction to two realms of subject matter that are universally agreed to be outside the scope of property rights. At one end of the spectrum are the basic building blocks of sensory and expressive intelligibility: colors and basic shapes, musical notes, "words and short phrases such as names, titles, and slogans[,] familiar symbols or designs [,] mere variations of typographic ornamentation, lettering or coloring."164 Everyone is obliged to use these building blocks in order to think or communicate anything; no one is permitted to have property in them as such. Only particular selections, coordinations, and arrangements of such elements are potentially within the realm of protectable subject matter. ${ }^{165}$ At the other end of the spectrum are intellectual abstractions pure and simple: ideas, concepts, and principles. ${ }^{166}$ Only specific concrete forms in which these abstractions may be captured and expressed are potentially copy-

162. See 17 U.S.C. $\$ 102$ (2006) ("Copyright protection subsists, in accordance with this title, in original works of authorship . . ..").

163. HOUSE REPORT, supra note 149, at 56 (emphasis added).

164. 37 C.F.R. $\$ 202.1$ (2011) ("Material not subject to copyright.").

165. In this sense, all copyrightable works meet the definition of "compilations." A compilation is a work formed by the collection and assembling of preexisting materials or of data that are selected, coordinated, or arranged in such a way that the resulting work as a whole constitutes an original work of authorship. See 17 U.S.C. $\$ 101$.

166. 17 U.S.C. $\S 102$ (b) ("In no case does copyright protection for an original work of authorship extend to any idea, procedure, process, system, method of operation, concept, principle, or discovery, regardless of the form in which it is described, explained, illustrated, or embodied in such work."). 
rightable, and to the extent we fear that a given idea is capable of capture in only one or very few such forms, "merger doctrine" will deny property in those forms in order to avoid granting it in the idea. ${ }^{167}$ Anything between these two extremes is labeled expression. So long as a given quantum of expression satisfies the standard of "originality"-i.e., it was not copied, and it exhibits some "minimal degree of creativity" - ${ }^{168}$ and is not weeded out by merger doctrine, it qualifies as protected expression. ${ }^{169}$

This notion of protected expression, in turn, plays a large role in the doctrine of substantial similarity, which seeks to answer the question of how similar something must be to a work of authorship in order to count as an infringing copy of it. What do we mean by protected expression? The answer ought to be that protected expression really means only "those elements of a work of authorship of which we will take cognizance when comparing it with putative copies to decide whether they embody the work." Unfortunately, some copyright decisions reflect a different understanding in which protected expression might be described as "material that, if reproduced in sufficient quantity, constitutes a copy of the work from which it is taken."

An example of the latter approach is Castle Rock Entertainment v. Carol Publishing Group, Inc., ${ }^{170}$ which concerned the "Seinfeld Aptitude Test," a quiz book "containing 643 trivia questions and answers about the events and characters depicted in Seinfeld." 171 The Second Circuit thought it irrelevant to the question of substantial similarity that the defendants' book of Seinfeld trivia was "a totally random and scattered collection of questions relating to events that occurred in the shows," presented in a sequence having "no relationship to the sequences of any of the Seinfeld episodes." 172 Because the court located information about the doings of fictional characters within the realm of protected expression, and found that the quantity of such expression reproduced in the book was "more than 'de minimis," 173 this was sufficient to render the quiz book substantially similar to the television series. ${ }^{174}$

The problem with the Castle Rock approach to substantial similarity is that it treats the author's expression as a sort of undifferentiated sub-

167. See, e.g., Morrissey v. Procter \& Gamble Co., 379 F.2d 675, 679 (1st Cir. 1967) (stating that where topic necessarily requires one of only limited number of forms of expression, "the subject matter would be appropriated by permitting the copyrighting of its expression").

168. Feist Publ'ns, Inc. v. Rural Tel. Serv. Co., 499 U.S. 340, 344-45 (1991).

169. See Castle Rock Entm't, Inc. v. Carol Publ'g Grp., 150 F.3d 132, 139 (2d Cir. 1998) (finding created facts about fictional characters to constitute "protected expression").

170. 150 F.3d 132 (2d Cir. 1998).

171. Id. at 135 .

172. Id. at 140 .

173. Id. at 137-38 (quoting Ringgold v. Black Entm't Television, Inc., 126 F.3d 70, 75 (2d Cir. 1997)).

174. See id. at 141. 
stance, which, if present in sufficient quantity, necessarily constitutes a copy of the work of authorship. This is like saying that a pail of sand on my desk (so long as it is substantial enough) constitutes a copy of the sand castle I scooped it from. Copyright protection does not attach to expression, it only attaches to a work of authorship. ${ }^{175}$ It is true that the protectable identity of a work has to be located within the realm of expression. It does not follow that quanta of original expression are protected per se, or that the threshold of protection is simply a matter of quantity. Not everything brought into being in the course of an act of authorship is itself a work of authorship. Just as the dismantled wood of Theseus's ship is no longer the ship if piled up in a warehouse, disembodied fragments of expression do not a work make.

A classic treatment of substantial similarity that keeps focus on the identity of the work of authorship is Judge Learned Hand's opinion in Sheldon v. Metro-Goldwyn Pictures Corporation. ${ }^{176}$ There, the owners of a play sued the makers of a film. Both the play and film were based on a documented true story that had already served as the basis for a fictionalized book, making it necessary to filter out preexisting material to identify the protected expression at issue. ${ }^{177}$ Judge Hand did not, however, ask simply whether some non-negligible quantity of expression particular to the play had been incorporated into the film. Rather, he carefully parsed both the overall dramatic effect of the play and the interrelations of the means by which that effect was produced, describing the protected work as the "sequence of the confluents of all these means, bound together in an inseparable unity." 178 Judge Hand found infringement even though the dialogue and other sensory elements of the two works were not identical, because the "dramatic significance" of the scenes was identical, and had been achieved through identical dramatic elements. ${ }^{179}$ A simpler way to express the test-and hence more amenable to the in rem system we are seeking to construct-was articulated by Judge Hand elsewhere: "[It is infringement if] the ordinary observer, unless he set out to detect the disparities, would be disposed to overlook them, and regard their aesthetic appeal as the same." 180

By using the term "expressive experience," I mean to invoke a standard of copying at least as stringent as Judge Hand's, one that locates the protected identity of a work of authorship at a level of comprehensive coherent significance designed to have desired effects on some audience. In judging whether a non-verbatim, putative copy actually embodies a copy-

175. See 17 U.S.C. $\$ 102$ (2006) (“Copyright protection subsists, in accordance with this title, in original works of authorship ....").

176. 81 F.2d 49 (2d Cir. 1936).

177. See id. at 49.

178. Id. at $55-56$.

179. Id. at 56.

180. Peter Pan Fabrics, Inc. v. Martin Weiner Corp., 274 F.2d 487, 489 (2d Cir. 1960). 
righted work, we should compare the expressive experience of the original work with that encoded in the copy, and evaluate the significance of the dissimilarities between them in light of our judgments as to the nature and qualities of the expressive effects the original work was designed to give rise to. Where most qualified audience members can be expected to regard these experiences and their effects as having essentially the same utility despite the alterations, the copy should be regarded as embodying the original work.

We can analogize this inquiry to the one we would engage in when deciding whether alterations made to a wooden chair have destroyed its identity as an object of ownership. First of all, note that our identification of the object as a "chair" is based on objective judgments about its form and the range of useful purposes that form can be expected to offer potential users. We assume that whoever made the object intended it to be a chair, but our identification of it as such is not dependent on any interrogation of the carpenter's subjective desires. Similarly, in copyright, our judgments about the identity of a work do not depend on any investigation of the author's intent except to the extent that this intent has been made manifest in the form of the work itself. There are many alterations one might make to a chair without destroying its identity as such-one might repaint or reupholster it, carve one's initials in the seat, or attach a neck rest. It is only when the wood is pressed into another purpose superseding the original one that it ceases to be a chair and becomes something else, as when I take its pieces apart and use them as part of the building material for a tree house ladder. At this point, we may trace recognizable pieces of wood, but the chair is gone, and title to it is moot. Similarly, when qualified audience members would not recognize a copy as giving rise to an expressive experience that duplicates the utility of the original work by offering essentially the same expressive effects, the original work is not present even though we can identify recognizable material from the original that has been incorporated into the secondary work.

\section{F. The Right to Exclude in Copyright}

The most straightforward way to give authors an ability to reap exchange value based on their work would be to give them the exclusive right to authorize beneficial uses of that work. In an ideal world-ideal, at least, from the perspective of copyright enforcement-there would be some way of detecting when people were making beneficial use of a work, and preventing it if unauthorized. Since we cannot (thankfully) police what is going on inside people's minds, however, we need a proxy at least one step removed from this. For people to make beneficial use of a work, they must first be provided with access to the sensory data of which it is composed. Providing this access involves physical acts that can be detected, and that can thus serve as interception points for the imposition of property rights. If we describe authors as having a basic "right" to realize 
whatever exchange value (if any) their works of authorship are capable of commanding, then the correlative duty imposed on others would be to refrain, absent authorization, from satisfying demand for those works by taking actions that make them available for beneficial use, whether by oneself or others. An act potentially satisfies demand for a work when it enables someone to make beneficial use of that work without dealing with the author (or someone whose rights derive from the author). This is what constitutes consumptive use in the context of copyright-actions that consume opportunities for authors to decide whether their work will be made available to a potential user.

As with tangible property, ${ }^{181}$ consumptive uses do not necessarily do harm to authors' actual ability to realize exchange value based on beneficial use of their work. If I lend you a copy of a book (thus enabling you to make beneficial use of the literary work embodied in it), and for whatever reason you do not read it before I demand its return, your demand for the work has not been satisfied. Or if I lend you a copy of a book that, in fact, you would never have been willing to pay to read, and you wind up reading it, the demand for the work has not been diminished from what it would have been absent my action. ${ }^{182}$ It may even be the case that you read the book and as a result your demand is increased, so that you decide to purchase your own copy anyway. Finally, if I display a copy of a work to you solely for the purpose of communicating second-order information, and your perception of the copy serves that purpose alone, then demand for beneficial use of the work has not been impacted.

Because judgments as to which consumptive uses actually harm the author's protected interest are likely to be as troublesome as judgments about which possessory uses actually interfere with an owner's intended use, there will be good reason to move to a bright-line right to exclude. In copyright, the exclusion encompasses certain enumerated classes of consumptive uses deemed to be those through which the exchange value of a work is most likely to be realized. ${ }^{183}$ As with the categorical exclusion of 50.

181. For a further discussion, see supra, four paragraphs of text following note

182. For this assertion to hold strictly true, we would also have to assume that no one would ever have been willing to pay for the privilege of enabling you to read the book for free.

183. See 17 U.S.C. $\$ 106$ (2006) (providing exclusive rights). The rights provided are:

(1) to reproduce the copyrighted work in copies or phonorecords;

(2) to prepare derivative works based upon the copyrighted work;

(3) to distribute copies or phonorecords of the copyrighted work to the public by sale or other transfer of ownership, or by rental, lease, or lending;

(4) in the case of literary, musical, dramatic, and choreographic works, pantomimes, and motion pictures and other audiovisual works, to perform the copyrighted work publicly;

(5) in the case of literary, musical, dramatic, and choreographic works, pantomimes, and pictorial, graphic, or sculptural works, including the 
possessory uses of tangible property, the scope of each of these classes needs to be justified and calibrated so as not to restrict people's freedom of action to an extent unjustified by probable harms to authors' protected interests and the costs of identifying them. There is much to be said on this score with regard to each of the classes enumerated in 17 U.S.C. $\S 106$. In particular, the reproduction right has become overbroad given the advent of digital technology and internet communication. Whereas it made sense to assume that each printed copy of a book was intended (and likely) to satisfy demand for the work on the part of at least one reader, a single beneficial use of a work may now involve the making of numerous copies. ${ }^{184}$ For this reason, the reproduction right needs to be revised-a task I will not attempt here. ${ }^{185}$

On the other hand, if there is any area in which a bright-line trespass rule seems warranted, it would be the unauthorized distribution, public performance, or public display of complete, verbatim, full scale, full resolution reproductions of a work of authorship. Apart from any privileged uses we may wish to exempt, it makes sense that such acts should be categorically excluded, even though some of them may not actually constitute or result in beneficial uses of the work. This is an acceptable discrepancy, because such copies clearly facilitate and draw most of their value from beneficial uses of the work, and the costs of attempting to detect and distinguish actual beneficial uses of the work from other uses of the copies would be too high.

Professor Balganesh argues that, in order to properly tie rewards to incentives, we should leave out of the right to exclude any uses of the work that were not foreseeable at the time of its creation, ${ }^{186}$ and he treats the particular technology by means of which that use is effected as forming

individual images of a motion picture or other audiovisual work, to display the copyrighted work publicly; and

(6) in the case of sound recordings, to perform the copyrighted work publicly by means of a digital audio transmission.

Id.

184. See, e.g., Jessica Litman, Digital Copyright: Protecting Intellectual Property on the Internet (2001); Mark A. Lemley, Dealing with Overlapping Copyrights on the Internet, 22 U. DAYTON L. Rev. 547, 555 (1997) (counting seven different copies made in connection with display of work transmitted over computer network). While this overbreadth would be ameliorated to a large extent by excluding RAM copies from the definition of infringing copies, see Cartoon Network LP v. CSC Holdings, 536 F.3d 121, 127-30 (2d Cir. 2008) (holding that transmission of copyrighted work through RAM buffer that holds each fragment of work for no more than 1.2 seconds does not result in creation of copy within meaning of Copyright Act), the nature of the relationship between reproduction and beneficial use has changed dramatically and needs to be revisited.

185. For an excellent analysis of the distinctions this recalibration should focus on, see Matthew Sag, Copyright and Copy-Reliant Technology, 103 Nw. U. L. Rev. 1607 (2009).

186. See Balganesh, supra note 156 , at 1575 . 
part of the definition of the use that has to have been foreseen. ${ }^{187}$ In my view, the relevant foreseeability pertains to the manner in which interaction with the work will impart expressive benefits to the user, not to the technical means through which that interaction will take place. So long as people are perceiving the sensory experience designed by the author in order to derive benefits from the expressive experience she sought to convey, they are using her work in precisely the way she intended regardless of whether the viewing takes place via projector, television broadcast, DVR, or cosmic brainwave. Balganesh's approach eschews the informational advantages of uniform in rem duties, by making the range of permitted uses of any given work depend on highly specific inquiry into the state of known and foreseen technologies at the time of its creation.

I would suggest rather, that a use should be regarded as unforeseeable to the author, and consequently outside the author's rights, when we can say with confidence that the benefits derived from a putative copy of the work do not stem from recreation of the expressive experience the author designed. This will be the case when the nature and quality of the copy, and the use made of it, are not tailored to facilitate beneficial use of the work as presented by the author, but rather to communicate secondorder information, or to give rise to expressive experiences (and resulting benefits) radically discontinuous from the ones the author designed. In order to comply with the in rem principle, any judgments we make about what the author designed must be based not on investigation of the author's subjective intent, but on the socially intelligible information presented on the face of the work and in connection with its publication.

\section{G. The Meaning of "Derivative Work"}

Properly speaking, a derivative work is one designed to convey substantially the same expressive experience as an original work, but to do so through a modified sensory experience so as to be accessible or desirable to a different audience. Most of the enumerated examples given in the statutory definition ${ }^{188}$ - translation, musical arrangement, dramatization, fictionalization, motion picture version, sound recording, art reproduction-involve translation, either into a different medium or into a differ-

187. See id. at 1612-13 (suggesting that if musical work was composed in 1955, recording it on VCR should not qualify as infringement, because video recording is "markedly different" from means of accessing work that were known or foreseeable when work was made).

188. See 17 U.S.C. § 101.

A "derivative work" is a work based upon one or more preexisting works, such as a translation, musical arrangement, dramatization, fictionalization, motion picture version, sound recording, art reproduction, abridgment, condensation, or any other form in which a work may be recast, transformed, or adapted. A work consisting of editorial revisions, annotations, elaborations, or other modifications which, as a whole, represent Id. an original work of authorship, is a "derivative work." 
ent idiom of the same medium. The others-abridgment and condensation-retain the same medium and idiom, but seek to convey the same experience in a more accessible form by reducing the amount of sensory input an audience needs to digest. Additions contemplated by the statutory definition, on the other hand, such as annotations or elaborations, leave the original work mainly intact but seek to render more easily accessible some of the layers of meaning that might be extrapolated from the expressive experience of the work. The definition's conceptual summation-"or any other form in which a work may be recast, transformed, or adapted"-strongly suggests the persistence of the original work's identity into the derivative work (the statute does not say, "in which non-de minimis portions of a work may be recast ...."). Notably, while the statute provides an exclusive right to "prepare" derivative works, it does not provide any exclusive rights to make or distribute copies of such works, or to publicly perform or display them. ${ }^{189}$ For any of those things to be actionable then, the derivative work must share identity with the original such that a copy of the one qualifies as a copy of the other. ${ }^{190}$

The above implies that a derivative work is always a potential substitute for the original. This is not to say that no one consumes both originals and derivatives; many individuals belong to multiple audiences, and whether a derivative work actually serves as a substitute or complement for the original will vary depending on the individual. Some people may wish to read a book in more than one language. Fans of some books will be eager to consume them in movie form as well (or vice versa). For a work to be properly described as a derivative work, however, we must be able to say that at least some people otherwise interested in the expressive experience of the original could have their demand for it satisfied by consuming the derivative instead. This is the only justification for including uses of copies of derivative works within the author's right to exclude, even though there is no statutory basis for doing so; such copies are intended to satisfy demand for the same expressive experience designed by the author. The content and quality of this experience, to be sure, will inevitably be altered by the changes made to create the derivative work. The degree of such alteration is limited, however, by the aim of preserving the original experience enough to make its specific value accessible to different audiences. This will be true whether one is making a derivative work in order to openly market it as such, or whether one is attempting to get away with appropriating the value of the original while pretending to make an original work.

189. See 17 U.S.C. $\$ 106$.

190. See Nimmer \& Nimmer, supra note $6, \S 8.09$ [A] (suggesting that for this reason, the derivative works right "may be thought to be completely superfluous"). 


\section{H. Distinguishing Derivative Works from Transformative Non-Uses}

To decide whether something is a derivative work, one must first identify the nature of the original work. ${ }^{191}$ This means focusing on the nature of the expressive experience the work is designed to give rise to, the means by which that experience is created, and the qualities of the expressive benefits the experience is designed to confer. Take a fictional novel such as Harry Potter and the Sorcerer's Stone. ${ }^{192}$ Such a work is designed to engage and lead the reader through a series of thoughts and emotions that arise from contemplating certain characters engaged in certain actions and involved in certain events. The qualities of the experience depend not only on those of the characters, setting, and plot, but on the specific order and manner in which information about them is revealed to the reader, as well as the literary devices through which they are conveyed.

\section{Translations of Idiom or Medium}

As we saw in the case of transformed tangible things, common linguistic usage can be a useful tool in helping to gauge whether an alleged derivative work shares the requisite identity with the original. While I would not claim that this is a sufficient test, surely a derivative work must be of a nature that people would commonly describe as a different version or edition of the original work. Few, for example, would hesitate to describe a competent and faithful translation of Harry Potter and the Sorcerer's Stone into French in this way. To be sure, the expressive experience of the French reader is not perfectly identical to that of an English reader, as certain flavors and nuances of language cannot be perfectly translated, which is why there are no doubt many poems that one should hesitate to call the "same work" after translation. Yet the sorts of nuance likely to be lost in translation form a very small portion of the expressive experience of Harry Potter. The overall narrative, the characterizations, and the sequence and structure of events through which both are experienced-all would be complete and identical in the French version.

Much the same is true of the actual film version of Harry Potter and the Sorcerer's Stone ${ }^{193}$-though this is far from always the case with purported "motion picture versions" of literary works. ${ }^{194}$ The translation into a different medium necessarily means that significant portions of the book's

191. See Michael Abramowicz, A Theory of Copyright's Derivative Right and Related Doctrines, 90 MinN. L. REV. 317, 378 (2005) ("Modifications have meaning only with respect to what is being modified, and whether modifications cumulatively represent an original work necessarily depends on the degree to which the modified work is transformed.").

192. J.K. Rowling, Harry Potter and the Sorcerer's Stone (1998).

193. HARry PotTer AND the Sorcerer's Stone (Warner Brothers 2001).

194. See Benjamin Kaplan, AN Unhurried View of Copyright 57 (1967) ("It is surely wrong to assume that what Hollywood is content to call a dramatization or screen treatment of a novel or play would necessarily be an infringing copy if not licensed."). 
expressive content will be omitted or altered, and much information that was conveyed through words will now be conveyed through visual images and sounds. Nevertheless, the narrative content, structure, and characterizations from the book retain their identity to such an extent that a viewer of the film could surely provide an account of the resulting expressive experience that would coincide to a high degree with one provided by a reader of the book. Where this is not the case, the film is not really a derivative work of the book, though it may have been licensed and marketed as one.

\section{Sequels}

Sequels are generally assumed to constitute derivative works, ${ }^{195}$ but it is difficult to understand how one can justify this conclusion through internal reasoning. ${ }^{196}$ A sequel does not "recast, transform [ ], or adapt[ ]" the work it is based upon. ${ }^{197}$ Harry Potter and the Chamber of Secrets ${ }^{198}$ is in no sense a different version of Harry Potter and the Sorcerer's Stone. The two works have elements in common, but identifying and describing those common elements alone would not suffice to convey the expressive experience of either work. Reading Chamber of Secrets would not enable one to recreate the intellectual experience of reading Sorcerer's Stone, or vice versa. Someone who read only the second book could at best try to extrapolate what the characters depicted there would have thought, felt, said, and done under different circumstances. The second book provides only rudimentary indications as to what those circumstances were, and none at all as to the narrative structure through which they were conveyed. We will reserve for later the question of whether a literary character or setting should ever be regarded as constituting its own freestanding expressive experience whose appearance in another work thus constitutes a derivative work. As a general matter, however, a sequel is not a derivative work of the original literary work whose story it seeks to continue.

\section{Abridgments and the Problem of "Fictional Facts"}

Drawing the precise line beyond which abridgements cease to be derivative works can be difficult, but stating the nature of the inquiry is not. An abridgment attempts to preserve the expressive experience of the original, making it more accessible to certain audiences by omitting or curtailing (what the editor deems to be) nonessential elements. By contrast, a synopsis seeks only to give bare bones information-facts-as to the conceptual content of the book, and not to convey the experience of reading

195. See Suntrust Bank v. Houghton Mifflin Co., 268 F.3d 1257, 1274 (11th Cir. 2001).

196. To be sure, there are arguments based on external reasoning as to why sequels should be within the exclusive rights of the author. See, e.g., Abramowicz, supra note 191 (arguing for this result to avoid rent dissipation).

197. Id. at 325 (internal quotation omitted).

198. J.K. Rowling, Harry Potter and the Chamber of Secrets (1999). 
it or the expressive-as opposed to informational-benefits one would gain from doing so. The two do not serve different audiences for the same expressive work, but two groups of consumers seeking fundamentally different things. There are some people who would like to approximate the expressive experience of reading War and Peace, but do not think they can make it through 1,400 pages. They form the audience for an abridgment. There are other people who have no desire for the experience of reading War and Peace, but just want to know enough about what the book contains to be culturally literate, or to pass an exam. They form the market for a synopsis (at least one such market), and there will often be a way to give them what they want that does not amount to beneficial use of the work of authorship, but only to communication of factual information about it.

This distinction between the expressive experience of a work and factual information about its contents is fairly well understood when it comes to non-fiction works, ${ }^{199}$ but it has unfortunately been muddied in the realm of fiction. All agree that, as the Supreme Court made clear in Feist Publications, Inc. v. Rural Telephone Service Co. ${ }^{200}$ facts are not copyrightable. ${ }^{201}$ The reason the Court gave for this is that "facts do not owe their origin to an act of authorship." ${ }^{202}$ Relying on this statement, the Second Circuit in Castle Rock reasoned that facts about fictional characters are protected by copyright, because they do owe their origin to an act of authorship. ${ }^{203}$ In so doing, the Second Circuit transformed what had been presented as a necessary requirement for copyrightability into a sufficient one.

The Court's statement in Feist that "facts do not owe their origin to an act of authorship" seemed to make sense within the context of Feist, which focused on the collection and presentation of facts consisting of persons' addresses and phone numbers. ${ }^{204}$ If taken literally and categorically, however, it is clearly false. Let us define a fact as "the informational content of

199. See Harper \& Row Publishers, Inc. v. Nation Enters., 471 U.S. 539, 584 n.7 (1985) (Brennan, J., dissenting) ("Copyright protection cannot be extended to factual information whenever that information is interwoven with protected expression ... into an expressive 'totality.' ... Precluding subsequent use of facts so presented cannot be squared with the specific legislative intent, expressed in both House and Senate Reports, that '[c]opyright does not preclude others from using the ... information revealed by the author's work.' (alteration in original) (citations omitted)).

200. 499 U.S. 340 (1991).

201. See id. at 344 (discussing intersection of inability to copyright facts with ability to copyright compilations of facts).

202. Id. at 347 .

203. See Castle Rock Entm't, Inc. v. Carol Publ'g Grp., 150 F.3d 132, 139 (2d Cir. 1998) ("Unlike the facts in a phone book, which 'do not owe their origin to an act of authorship,' each 'fact' tested by The SAT is in reality fictitious expression created by Seinfeld 's authors." (citation omitted)).

204. Feist Publ'ns, 499 U.S. at 342-43. 
a true statement about the world."205 Here is one such statement: "Former President Gerald Ford wrote a memoir about his time in office." This is a statement of fact, and yet the fact stated owes its origin to Gerald Ford's act of authorship. Had he not acted as an author, my statement would not be factual. Here is another statement of fact: "As described in the first book in which he appeared, the fictional character Harry Potter has a lightning bolt-shaped scar on his forehead." Can there be any doubt either that this is a statement of fact or that the fact stated owes its origin to an act of authorship? Acts of authorship, like all other acts and events, change the state of the world and therefore originate new facts. That does not make those facts works of authorship.

The Court in Feist was attempting to retire "sweat of the brow" theories of copyright that sought to protect, not only the exchange value of an expressive experience designed by an author, but also value resulting from the effort involved in discovering and compiling information. ${ }^{206}$ The reasoning of Castle Rock implicitly sets up a new sweat of the brow theory: that copyright should protect, not only the value of the expressive experiences created by authors, but the value of all new information generated as a result of the author's intellectual labor in designing those experiences. What the Court in Feist should have said is simply that copyright does not protect information-whatever its origin-but only original expressive forms (i.e., works) in which it may be presented so as to create specific effects in a human mind. ${ }^{207}$

This does not mean that one can avoid liability for infringement simply by reporting verbatim the entire contents of a book prefaced by the phrase, "The contents of the book Harry Potter and the Sorcerer's Stone are as follows." 208 The issue is not whether one's actions may properly be described as reporting facts. The issue is whether one's actions permit people to make beneficial use of the expressive work one is describing. This requires us to focus on the accused copy and ask whether it is capable of giving rise to anything close to the same expressive experience as the origi-

205. Or, if you prefer, facts may be defined as those aspects of reality rendering the statement true. It makes no difference to my argument.

206. Feist Publ'ns, 499 U.S. at 352.

207. See Register of Copyrichts, Register's Report on the General ReviSION OF THE U.S. Copyright LAW 3-6 (1961), reprinted in 8 Nimmer \& Nimmer, supra note 6, app. 16 ("Copyright does not preclude others from using the ideas or information revealed by the author's work. ... [A]nyone is free to create his own expression of the same concepts, or to make practical use of them, as long as he does not copy the author's form of expression." (emphasis added)).

208. See Nihon Keizai Shimbun, Inc. v. Comline Bus. Data, Inc., 166 F.3d 65, 72 (2d Cir. 1999) (holding abstracts of financial news articles infringed where they tracked exact structure and organization of facts presented); Wainwright Sec., Inc. v. Wall St. Transcript Corp., 558 F.2d 91, 96-97 (2d Cir. 1977) (rejecting contention that plaintiff's financial reports were "news" of which defendant's abstracts were "coverage," where informational substance of reports and "manner of expression" were reproduced), abrogated by Salinger v. Colting, 607 F.3d 68 (2d Cir. 2010). 
nal work. There are various useful heuristics we can use to approach this question. As when tracing the identity of tangible objects, attention to continuity and specification can be telling. If the accused work contains fragments of expression from the original-even numerous ones-but those fragments are so radically rearranged that no one would describe the result as constituting a different "version" or "edition" of the original work, it is likely not a derivative work. Another way to get at this is to borrow the reversibility proviso from the media sententia. Here, the question would be whether it is possible, working only from a copy of the accused work, to generate a recreation of the expressive experience of the original work robust enough to meet the test of substantial similarity employed by Judge Hand in Sheldon. ${ }^{209}$

The Seinfeld Aptitude Test at issue in Castle Rock would clearly fail to qualify as a derivative work under this standard-it was based on a series of dramatic works, yet the information it provided would not enable a reader to glean the overall storyline or dramatic effect of a single episode, much less the series taken as a whole. It is difficult to imagine anyone not already familiar with the original works enjoying the book much at all, let alone regarding it as a substitute for seeing them. The Harry Potter Lexicon, an encyclopedia detailing all characters and items appearing in the Harry Potter series, is a more difficult case, as the comprehensive nature of the information it provides approaches nearer to the line separating factual synopses from expressive abridgments. ${ }^{210}$ The mere fact-emphasized by the district court in holding the reference book to infringe the novelsthat the Lexicon contained numerous quotations of language from the books is not as important in my view as the extent to which the interrelations of those quotations with the information given about characters, plot elements, and narrative sequence would enable one to generate robust recreations of the expressive experience gained from reading the novels. ${ }^{211}$ It is certainly conceivable for something presented as a "reference" to preserve so much of the expressive character of the underlying works that it does amount to a different version of them-simultaneously abridging and annotating the originals in such a manner that some people interested in the expressive experience of the originals might plausibly think it a satisfactory substitute. So long as the question is properly

209. For a further discussion of the law under the substantial similarity test, see supra notes $177-80$ and accompanying text. Note that this test is not the one rejected in Horgan v. Macmillan, Inc., 789 F.2d 157 (2d Cir. 1986). There is a difference between recreating the expressive experience of the original and recreating the full sensory experience of the original.

210. See Warner Bros. Entm't Inc. v. RDR Books, 575 F. Supp. 2d 513, 525 (S.D.N.Y. 2008) (explaining that author and publisher of series of fictional works sued author of encyclopedic work covering "every item and character that appears in the Harry Potter works, no matter if it plays a significant or insignificant role in the story").

211. See id. at 527. 
framed in this manner, truly close cases can be decided in favor of the original author.

\section{Uses of a Work to Convey Second-Order Information}

We have noted that it is possible to make beneficial use of a copy of a work without making beneficial use of the work itself. Of course, merely asserting a transformative purpose is not sufficient to remove a copy from the scope of the author's exclusive rights-you cannot establish specificatio simply by sitting on someone's car and announcing that you have thereby transformed it into a chair. The in rem principle requires that such an assertion be buttressed by some objectively recognizable transformation in the sensory qualities of the copy used, one that both renders the repurposing manifest and hinders use of the copy to make beneficial use of the copyrighted work. Otherwise the judgment that the use is non-conflicting turns entirely on assertions about the internal state of mind of those doing the using.

The decisions in Kelly v. Arriba Soft Corp..$^{212}$ and Bill Graham Archives v. Dorling Kindersley $L t d .^{213}$ each invoked this principle in finding that the copied images at issue constituted transformative fair uses. In each case, the allegedly infringing image had been presented in both a context and a format designed to facilitate second-order informational uses rather than consumption of the aesthetic expressive experiences the works were designed to convey. Key to both holdings was that the copies in question were reduced in size and resolution in a manner that substantiated the repurposing. ${ }^{214}$

This same rationale would apply to the incidental capture of part of a film, television broadcast, or work of visual art in the background of a filmed scene. The purpose of including such images in the resulting work is not to enable beneficial use of the work incidentally captured, but to convey second-order information about the fact of this work being displayed in a given context. Where such informational use is bona fide, this will be reflected in the quality of the capture. No one could plausibly

212. 336 F.3d 811 (9th Cir. 2003). Kelly involved the owner of photographs who sued an internet search engine over thumbnail versions of works that were displayed in connection with search results. See $i d$.

213. 448 F.3d 605 (2d Cir. 2006). Bill Graham Archives involved the owner of artwork-specifically, Grateful Dead concert posters-who sued over a book recounting of the history of the band that included reduced scale reproductions of the posters as historical material. See id.

214. See id. at 611 ("While the small size is sufficient to permit readers to recognize the historical significance of the posters, it is inadequate to offer more than a glimpse of their expressive value."); Kelly, 336 F.3d at 819 ("Furthermore, it would be unlikely that anyone would use Arriba's thumbnails for illustrative or aesthetic purposes because enlarging them sacrifices their clarity."); see also Núñez v. Caribbean Int'l News Corp., 235 F.3d 18, 25 (1st Cir. 2000) (holding newspaper reproduction of modeling photo to be fair use, stating "a newspaper front page is simply an inadequate substitute for an 8" x 10" glossy"). 
regard a "4.5-second serendipitous shot of Homer Simpson, out of focus and with no sound, on the television in the background," 215 depicted in a documentary about the lives of opera stagehands, as enabling one to recreate the expressive experience of whatever Simpsons episode was playing at the time. The same can be said of the garbled strains of Prince's song "Let's Go Crazy" audible in the background of the home video at issue in Lenz v. Universal Music Group. ${ }^{216}$ Such copies do not serve to facilitate beneficial use of the works captured, and an in rem approach to copyright would not permit authors to wield holdout power over their incorporation into other works.

\section{Non-Comprehensive Similarity}

\section{Component Works and Literary Excerpts}

In Harper $\mathcal{F}^{2}$ Row Publishers, Inc. v. Nation Enterprises, ${ }^{217}$ a book publisher sued The Nation over a 2,250-word article composed entirely of quotes, paraphrases, and facts drawn from the manuscript of Gerald Ford's memoir A Time to Heal. The direct quotes amounted to 300 words, which were, quantitatively speaking, "an insubstantial portion" of the manuscript. $^{218}$ Nevertheless, The Nation conceded that this copying would constitute copyright infringement if it did not qualify as fair use. ${ }^{219}$ In the course of ruling that it did not so qualify, the Court treated the market for "prepublication excerpts" as a part of the market for derivative works properly belonging to the author. ${ }^{220}$ This result is inconsistent with the concepts of work of authorship and derivative work developed thus far above. If the touchstone of identity is comprehensive similarity at the level of expressive experience, an "excerpt" cannot qualify as a copy, and hence its use in isolation cannot be infringing, even if the excerpt contains a great deal of the value of the work. Is this a defensible position? Aren't there any fragments of expression that are not mere sand-whose value lies only in the form of the castle-but gold, having standalone utility that deserves protection even outside the context of the specific work in which they are first presented?

Some works of authorship are large and complex enough to make taking in the entire expressive experience they convey impossible or inconvenient in a single continuous act of perception. This leads authors to

215. See Netanel, supra note 24, at 15-16 (describing how documentarian Jon Else was obliged to mask this footage in his film Sing Faster: The Stagehands' Ring Cycle because copyright owner demanded $\$ 10,000$ for its use).

216. See Lenz v. Universal Music Corp., 572 F. Supp. 2d 1150 (N.D. Cal. 2008) (involving YouTube user who sued record label over takedown notice issued against homemade video of child dancing on kitchen floor with Prince song playing in background).

217. 471 U.S. 539 (1985).

218. Id. at 564 .

219. See id. at 569.

220. See id. at 602-03. 
subdivide certain works into smaller sections, designed to be independently intelligible even though their full effect depends upon the viewer's ultimate perception of the whole work. Even where it is possible to take in the whole experience at once, some works are naturally composed of smaller, self-contained expressive experiences that have coherent meaning on their own, in addition to whatever extra benefits they may offer when viewed in relation to the larger work. Obvious examples would be the division of a book into chapters, a symphony into movements, or a dramatic work into acts or scenes. It would be counterproductive to force authors to choose one arbitrary level of organization at which their work will be presented, leaving them without recourse to prevent smaller component works from being distributed for beneficial use without permission. Some authors may wish to market these component works separately (e.g., in serialization) as well as simply including them within copies of the work as a whole. On the other hand, to permit owners to sue at will over use of any fragment taken from their work destroys the role of the work of authorship as an in rem limit to the scope of the author's rights and facilitates the proliferation of holdout problems. One might analogize this area to nuisance law, in which we recognize that there are non-trespassory acts that wrongfully interfere with owners' use and enjoyment of their property, but do not give owners carte blanche to decide what they are. As in nuisance law, we can ameliorate the problem by requiring complaining owners to meet standards of both objectively reasonable use and actual harm. ${ }^{221}$

The analog to the objectively reasonable use standard would be the requirement that the fragment allegedly infringed actually qualify as a component work of authorship in its own right, thus preserving the principle that protection inheres only in works, not quanta of expression. We can recognize bona fide component works because they exhibit socially intelligible indicia of having been designed as separable works of authorship: they are discrete, contiguous subsections, often set off from the rest of the work by sensorially distinguishable discontinuities (e.g., chapter breaks, cuts between scenes, spaces between tracks on a record album). They are designed in such a way as to present the audience with a coherent expressive experience that has at least some level of obvious standalone intelligibility and value outside the context of the work as a whole. Often (though not always) they are even given individual titles by the author. To the extent that there is any doubt about whether a given subset of the material presented to the public as a single work qualifies as a work in its own right, the author bears the burden of pointing out "the existence of those facts of originality, of intellectual production, of thought, and conception" that justify treating it as such. ${ }^{222}$ To satisfy the

221. For a further discussion of the law, see supra note 56 and accompanying text.

222. Burrow-Giles Lithographic Co. v. Sarony, 111 U.S. 53, 59-60 (1884). 
in rem principle, these facts must be discernible from the contours and contents of the fragment itself, not merely from extrinsic evidence as to the author's state of mind. The question is not merely whether the fragment in question has any expressive value, or whether the author intends or has actually attempted to charge people for its use. The question is whether third party duty-holders would readily recognize it as something designed by an author to be a work of authorship in its own right.

Applying this understanding to the excerpt from Ford's memoir, the proper approach would be to compare the Nation article, not to the book as a whole, but to whichever chapter or other discernible component work contained the material that the article reproduced. The question would then be whether the article constituted a copy or derivative work of any such component work. If the article amounted to a reproduction of the same expressive experience as such a component work (and interfered with the owner's own attempts to commercialize that component, as was the case in Harper $\mathcal{E}^{2}$ Row), it would be an infringing copy barring some privilege. Otherwise-if, for example, the article pulled together material taken from a number of different chapters in such a way as not to reproduce the expressive experience of any-then even if the cherrypicked material constituted the "heart of the book" in terms of its market appeal, ${ }^{223}$ this would not be a ground for finding copyright infringement. Copyright does not protect the mere assembly of valuable information. ${ }^{224}$

The above principles also provide an answer to one of the other problem cases cited by Netanel: that of Alan Cranston's unlicensed translation of Mein Kampf, meant to expose the misleading inaccuracy of the authorized English translation. ${ }^{225}$ While a complete, straightforward translation of the entire book would violate the right to exclude, we are told that Cranston's volume was in fact a "thirty-two-page newsprint pamphlet" that "heavily abridged Hitler's two-volume original but highlighted the ominous passages that Hitler's licensed translator had strategically expurgated," to which Cranston added "critical commentary unmasking Hitler's propaganda and distortions."226 Assuming that the "strategically expurgated passages" were dispersed throughout the book, it is likely that the approach proposed here would permit every one of them to be directly quoted without fear of infringement. Cranston would have to take care that his heavy abridgment of the rest of the work remained on the right side of the line discussed above, separating factual synopsis from expressive abridgment. It does not sound like compliance with such limits would necessitate much revision of the pamphlet Cranston published, or that

223. See Harper $\mathcal{E}$ Row, 471 U.S. at 564-65.

224. See Feist Publ'ns, Inc. v. Rural Tel. Serv. Co., 499 U.S. 340, 357 (1991) ("It is not enough for copyright purposes that an author collects and assembles facts.").

225. See Netanel, supra note 24 , at 14 .

226. Id. 
such revision would significantly detract from Cranston's ability to effectively sound the alarm about the true nature of Hitler's book.

\section{Song Melodies and Lyrics}

We can think of other obvious examples where it is non-controversial to treat a discrete aspect of a work as constituting a standalone work on its own, whether or not it was created or originally marketed in isolation. Think of a song whose lyrics and music were composed simultaneously by a single author. Such a work is defined in the statute as a "musical work [ ], including any accompanying words." ${ }^{227}$ It is nevertheless evident that the melody on its own constitutes a separable, self-contained work of authorship that may convey valuable expressive benefits even without the accompanying words. The same is true of the lyrics, which constitute a literary work in their own right whether or not they were initially presented as such. Either of these two component works may be used (and infringed) even though the other is omitted entirely.

The distinction between these two component works is often lost in discussions of "song parodies" alleged to be transformative uses. Such parodies generally use lyrics altered to an extent that clearly removes them from the realm of derivative work (as defined here) compared to the original lyrics. Take, for example, the song "Hey Sarah Palin," sung to the tune of "Hey There Delilah," a popular song by the group Plain White T's. ${ }^{228}$ The lyrics, which criticize (then VP candidate) Sarah Palin, have nothing in common with the lyrics to the original song other than an unprotectable meter and rhyme scheme, ${ }^{229}$ and for this reason do not constitute a copy or derivative work thereof. ${ }^{230}$ The melodies and instrumentation of the two songs, however, are absolutely identical. ${ }^{231}$ Under the in rem ap-

227. 17 U.S.C. $\$ 102$ (2006).

228. Venga Productions, Hey Sarah Palin, YouTube (Sept. 29, 2008), http:// www.youtube.com/watch?v=7DIc8jdra0o.

229. The first few lines of the original song are "Hey there, Delilah, what's it like in New York City/I'm a thousand miles away but girl tonight you look so pretty." The corresponding lines of the parody: "Hey Sarah Palin, do you tell them in Wasilla/That 4,000 years ago we roamed the planet with Godzilla."

230. Note that under my approach it is irrelevant to the question of transformative use whether the commentary contained in the parody is aimed at the original song or at something else, or even whether the song is "parodic" at all. If parody needs any special solicitude from copyright law, it should be afforded under the rubric of privileged uses.

231. This is in contrast to the 2 LiveCrew version of Roy Orbison's "Pretty Woman" at issue in Campbell v. Acuff-Rose Music, Inc., 510 U.S. 569 (1994). In this version, the character of the music was significantly altered in accordance with the rap style of the performers. The Court remanded in part for a determination of whether the accused song would interfere in the "market for rap derivatives." See $i d$. at 590 (evaluating factors of fair use defense). Instead of this inquiry, I would ask simply whether 2LiveCrew's recording was itself sufficiently similar to the expressive experience of the original composition to count as a derivative work. This is a different question from asking whether the recording derived some of its cachet from recognizable reference to the original song. 
proach outlined here, this cannot qualify as a transformative use of the music. Unless there is a category of privileged uses covering such parodies, they would remain within the exclusive rights of the composer. ${ }^{232}$ I do not regard this as an optimal result as far as my personal preferences are concerned, but nor do I assume that a properly calibrated system of in rem copyright will give free rein to every form of expression I enjoy.

\section{Video Clips}

Some video clips taken from larger works of authorship are clearly component works in their own right. Take Comedy Central's The Daily Show. The program is broadcast in the form of a continuous (apart from commercial breaks) half-hour episode, yet its content is readily divisible into a series of smaller, self-contained segments: host Jon Stewart's live monologue (itself often composed of comments on various discrete topics), an in-studio dialogue featuring Stewart and one or more other cast members, a filmed "location" story, a guest interview, etc. A two-minute excerpt from the show containing Stewart's comments on a given topic may well provide a complete and coherent expressive experience, and such segments are in fact offered in this form on Comedy Central's own website. There is no difficulty in finding such segments to be protected works in their own right, despite the fact that they are initially presented to the public as parts of a larger work.

Contrast this with the short clips from films or other audiovisual works used to create digital "mashups" of various kinds, such as homemade music videos in which a sound recording of a song is combined with thematically related video clips taken from some film or television series (often one having no intrinsic relation to the song). The video clips taken for this purpose each tend to be very short (seconds), and capture only a small fraction of a dramatic scene in the source work. Moreover, the soundtrack to the clips has been jettisoned to make way for the music recording. Each such clip undoubtedly has expressive value of some sort-recognizable characters, emotions, activity-otherwise the mashup artist would not have selected it. However, the particular moments excerpted were not designated in any way by the original author as standalone works, and it is difficult to imagine anyone wishing to watch one of these brief clips in isolation as a self-contained expressive experience. Mashup artists select which fragment of a film to clip based on its usefulness in serving as material for the expressive experience they are designing, not based on any coherent experience offered by the isolated fragment itself. Provided that such a mashup does not constitute an abridgment of the work from which the video clips are taken-which it

232. See Henley v. DeVore, 733 F. Supp. 2d 1144, 1156-60 (C.D. Cal. 2010) (deciding merits of lawsuit brought by Don Henley over use of melody to "The Boys of Summer" in political parody song used by candidate in Republican Senate primary). 
does only if the clips are selected and arranged in such a way as to convey substantially the same expressive experience as the original work-the fact that the video portion of it is composed entirely of clips from a single copyrighted work does not render it a derivative work, anymore than an outhouse is a copy of Theseus's ship simply because it is composed of planks taken from the latter.

\section{Sound Recording Samples}

It is a difficult question whether any given fragment from a single track of recorded music qualifies as a component work in its own right. Such tracks are generally not subdivided by their authors into readily discernible components analogous to the examples discussed above. One might nevertheless point to arguably natural points of subdivision-opening riff, verses, chorus, instrumental bridge, etc. With the advent of the ringtone market, the value of such fragments as standalone experiences is clearly demonstrated, but this does not necessarily lead to the conclusion that they are designed or should be regarded as works of authorship in their own right. At the very least, we would expect that to qualify as a component work, such a fragment should exhibit some obvious expressive coherency (an intelligible riff or melodic line) making plausible the claim that it was conceived as a complete expressive experience. Use of an unaltered sample of sufficient length and intelligibility to pass this test may constitute use of a component work properly within the exclusive rights of the author. On the other hand, uses of brief samples that lack the character of a component work, or that alter the sensory experience so as to create a radically different expressive experience, ${ }^{233}$ do not constitute copies or derivative works of the original recording.

\section{Characters and Settings}

What about fictional characters and settings? We have already said that a bona fide sequel-i.e., one that actually tells a different story from the original work-will usually not qualify as a derivative work, because it will not reproduce the expressive experience of the original work. Such a work will, however, necessarily incorporate elements of the original story (characters, settings, background storylines). Can such elements qualify as component works in their own right? In answering this question, we first need to be careful to specify exactly what we mean by "incorporate." The question is not, "To what extent does the value of the sequel stem from the existence of the original," but rather, "To what extent does the

233. See Bridgeport Music, Inc. v. Dimension Films, 410 F.3d 792 (6th Cir. 2005) (finding infringement where two-second sample from sound recording was copied, pitch was lowered, and copied piece was "looped" and extended to sixteen beats). Under my approach, such a use would not constitute use of any original work of authorship. 
sensory experience of the sequel enable someone to recreate the expressive experience embodied in the original?"

The intelligibility and expressive effect of any sequel will always depend largely on the reader's background knowledge of the original work-just as it depends on the reader's background knowledge of language and of the common experiences of life. A good sequel will find ways to invoke and build upon this world of information without directly spelling out the underlying reference, relying on the reader to make and appreciate certain connections. Such uses of the reader's knowledge do not recreate the expressive experience of the original work; they evoke the reader's knowledge of it. Only to the extent that the sequel itself reproduces expressive content somehow overlapping with the content of the original work is there any potential for infringement. In this view, the court in Anderson $v$. Stallone ${ }^{234}$ erred by holding a thirty-one-page treatment of a proposed Rocky sequel to infringe the three previous movies in which the "physical and emotional characteristics of Rocky Balboa and the other characters were set forth in tremendous detail."235 Presumably, none of this tremendous detail was actually reproduced in the treatment, which would have assumed the reader's knowledge of it, and focused instead on providing details of a new storyline involving those characters, none of which had been set forth in the earlier films.

To decide whether the story elements used in a sequel constitute a component work of authorship in their own right, we must first identify the set of all specific information about those elements that is expressed in both the original and the sequel. This will include any descriptions of those elements that are present in the original work and repeated in substantially similar form in the sequel, but not any information that is presented in only one of the works but not the other. Once this set of information has been identified, we must look at the manner in which the information was expressed in the original work and ask whether it has any coherence as a standalone work of authorship. If, for example, one were to take only the passages from Sorcerer's Stone conveying information about Harry Potter and his world that is also conveyed-conveyed, not evoked through tacit reference-by passages in Chamber of Secrets, would those passages form a coherent expressive experience showing the objective indicia of an independent work of authorship? Probably not: one would be

234. No. 87-0592 WDKGX, 1989 WL 206431 (C.D. Cal. Apr. 25, 1989).

235. Id. at *7. The notion that characters can be copyrightable independently of the works in which they appear stems in large part from dicta by Judge Hand in Nichols v. Universal Pictures Corp.:

But we do not doubt that two plays may correspond in plot closely enough for infringement. How far that correspondence must go is another matter. Nor need we hold that the same may not be true as to the characters, quite independently of the 'plot' proper, though, as far as we know such a case has never arisen.

Nichols v. Universal Pictures Corp., 45 F.2d 119, 121 (2d Cir. 1930). 
looking at a collection of non-contiguous snippets of prose that no author would attempt to market on their own.

We can imagine cases, however, in which the answer might be yes. Say, for example, that there is a chapter or scene in the original work describing a crucial event in the protagonist's life, and doing so in such a manner that it has plausible identity as a standalone component work. If the sequel recreates this event in comparable detail-whether through verbatim copying or not-then we would have to pass to the second question: whether the relevant passages in the sequel create an expressive experience substantially similar to that contained in the original work. If they do, then the sequel is indeed acting as a potential substitute in a market properly reserved to the original author. If not, then finding the sequel a derivative work is to give copyright protection to information rather than to a work of authorship.

The same analysis would apply to a work that is not a sequel but a retelling of the original story. In Suntrust Bank v. Houghton Mifflin Co., ${ }^{236}$ for example, the owners of the copyright to Margaret Mitchell's novel Gone With The Wind ("GWTW") sued over Alice Randall's The Wind Done Gone ("TWDG"), a novel reimagining the same basic story as GWTW from the perspective of the slave characters. ${ }^{237}$ The district court found Randall's book to infringe because of its incorporation of characters, plot elements, and settings from the original book. ${ }^{238}$ On appeal, the Eleventh Circuit held the book to be a fair use, finding it to be "a specific criticism of and rejoinder to the depiction of slavery and the relationships between blacks and whites in [GWTW]."239 In describing how this transformative purpose is achieved, the court provides information making it clear that TWDG should never have been held to be a derivative work in the first place.

Even if one assumes the original passages from GWTW describing the borrowed character attributes and plot elements to constitute a component work on their own, the manner in which those elements are depicted in TWDG is diametrically opposite and results in an expressive experience radically discontinuous from the one designed by Mitchell. ${ }^{240}$ TWDG is not analogous to a French translation or movie version of GWTW; it does not provide a different delivery vehicle for the experience Mitchell designed and sought to convey through the words of her novel. The district court found infringement based on its finding that the "average lay observer" would recognize characters and plot points to have been taken

236. 268 F.3d 1257 (11th Cir. 2001).

237. See id.

238. See Suntrust Bank v. Houghton Mifflin Co., 136 F. Supp. 2d 1357, 1367

(N.D. Ga. 2001), rev'd, 268 F.3d 1257 (11th Cir.).

239. Suntrust Bank, 268 F.3d at 1269.

240. See id. at 1270-73 (describing how narrative standpoint, theme, language, characterization, and story points conveyed by TWDG diverge radically from GWTW). 
from the original. ${ }^{241}$ This approach frankly treats ideas and information as protectable outside the confines of any work of authorship. ${ }^{242} \mathrm{Had}$ an in rem standard such as Judge Hand's test been applied, the absence of infringement would have been clear in that no reader could possibly be disposed to overlook the differences between the two works and "regard their aesthetic appeal as the same." 243 Resort to fair use analysis, with its value-laden inquiry into the social purposes served by Randall's novel, should be unnecessary.

\section{J. Accession Problems in Copyright}

The examples discussed above generally involve the copyright analogy to specificatio, in which subdivision and transformation of a work of authorship allegedly alter its identity to the point that the result is no longer the same work. There are also cases of accessio, where something that clearly qualifies as a copy of a work of authorship is being used, but the copy is being combined with other elements in such a way as arguably to prevent it from facilitating beneficial use of the work as such.

I stated above that video clips of the sort used to make a typical music video mashup ordinarily would neither infringe the full-length work from which they were taken, nor constitute component works of authorship in their own right. The soundtrack to the video is another matter. Such a soundtrack generally consists of an $\mathrm{mp} 3$ of a copyrighted recording of a song, used in its entirety. Given that there is no sensorial transformation of the sound recording whatsoever, the claim that this is a transformative use rests entirely on an alleged repurposing at the level of interpretation. The claim is that listening to the recording at the same time as viewing the images gives rise to a new overall meaning or experience radically different from that conveyed by either of its parts. One might make a similar claim on behalf of the song parodies discussed above, arguing that even though the song's melody is unaltered, that melody has been merged with the parodic lyrics into a larger whole so as to lose its original identity.

The weakness of these claims from an in rem perspective is that they rely on an assertion of repurposing that is not clearly substantiated by the sensorial attributes of the copy. The mere juxtaposition of additional material that adds layers of meaning to a work does not fundamentally alter the expressive experience conveyed by that work. This is why the definition of derivative works expressly includes works "consisting of editorial revisions, annotations, elaborations, or other modifications which, as a

241. See Suntrust Bank, 136 F. Supp. 2d at 1368.

242. See Harper \& Row Publishers, Inc. v. Nation Enters., 471 U.S. 539, 582 (1985) (Brennan, J., dissenting) ("[I]nfringement of copyright must be based on a taking of literary form, as opposed to the ideas or information contained in a copyrighted work.").

243. Peter Pan Fabrics, Inc. v. Martin Weiner Corp., 274 F.2d 487, 489 (2d Cir. 1960). 
whole, represent an original work of authorship."244 A normal music video of a song may add some additional meaning or entertainment value to that provided by the song, but someone watching it is still listening to the song. It is difficult to see how one can define such videos as transformative uses without concluding that owners of sound recordings and musical compositions should have no right to exclude synchronization uses of their works at all. What juxtaposed images would not alter the experience of listening to the song? Similarly, if we accept the premise that a reproduction or performance of a copyrighted musical composition qualifies as such despite omissions of or alterations to the accompanying lyrics, then it is not clear why parody songs are any different in this regard insofar as the question of transformation is concerned. ${ }^{245}$

Another way to say this is that, because the sensory content of the original sound recording is left intact and unaltered in the music video, there is no sense in which it has been rendered indivisible from the larger work-it is, in effect, merely "soldered" to the video, and can easily be separated by someone who wishes to enjoy it separately. ${ }^{246}$ There is thus little basis for any categorical confidence that distribution of the video is not equivalent to distribution of the original sound recording for beneficial use. To have a good argument for accession based on use of a complete, unaltered copy of a work, one would have to somehow embed it in a setting (such as a collage) in which, even though the entire work is present and perceivable, it is unlikely to be focused on in isolation or perceived for its own standalone expressive benefits. Thus, even if we were to accept the premise (rejected above) that brief samples of sound recordings necessarily constitute copies of the works, a collaged audio background of the sort once used in hip hop tracks would have a strong argument for noninfringement. ${ }^{247}$

We would reach the same results in these cases if we were to apply Justice Cooley's "relative value" approach. ${ }^{248}$ Even granting that the juxtaposition of song and video enhances the value of each, one would be hardpressed to say of any music video of which I am aware, that the value of the

244. 17 U.S.C. $\S 101$ (2006).

245. Again, such use may still fall within a category of privilege, though it is difficult to see which such category would save parody songs, since an exemption for "uses critical of the work used" would generally not apply if the work is the melody. To get there one would need an additional argument that once a melody becomes linked in the public's consciousness with a given set of lyrics-another form of indivisibility based on social norms-it is permissible to use the melody in conjunction with a parodic critique of the song lyrics or the cultural attitude expressed by the song as a whole. Even this would do nothing to save "Hey Sarah Palin," unless one wishes to simply privilege all uses of music to convey an entertaining political message.

246. For a further discussion of the law, see supra note 98 and accompanying text.

247. See Netanel, supra note 24 , at 20.

248. Wetherbee v. Green, 22 Mich. 311, 320-21 (1871). For a further discussion of the law, see supra note 133 and accompanying text. 
sound recording is anywhere approaching "swallowed up and rendered insignificant" by the value of the added video. ${ }^{249}$ On the other hand, one could say this of many of the brief individual samples used as fodder for a classic hip hop sound collage.

Another form of mashup with a relatively strong argument for accession would be the work of the DJ "Girl Talk," who takes vocal and instrumental tracks from various different popular and rap recordings, and layers them over each other, so that at any given moment the listener hears, for example, the vocal track from a rap song superimposed over an instrumental sample from one or more pop or rock songs. The various audio tracks are seamlessly mixed in the end result (i.e., "welded"), so that listening to it one cannot disaggregate them sensorially. Each Girl Talk track consists of a sequence of relatively short excerpts taken from numerous songs, with the result that the overall experience is radically different from that of listening to any of the individual recordings in its pristine state, and no one of them contributes more than a relatively small fraction of the overall value. To the extent that the clips used in such a work get longer and fewer in number, the argument that their identity has been superseded becomes weaker.

As a final, and more difficult, example of an accession analysis, take the various recent YouTube mashups featuring a climactic scene from Downfall, a German language film about the final days of the Third Reich. The original scene depicts Hitler in his bunker while his generals inform him of Berlin's inevitable capture by the Allied forces. A video clip of the scene has been reproduced in numerous videos, each of which reproduces the German scene as it appears in the film, but superimposes English subtitles to change the topic of the conversation (and Hitler's tirade) into something incongruous or humorous, such as the death of Michael Jackson, the shortcomings of the Apple iPad, or (in the ultimate meta-irony) the requests by the film's owners that such "parody" videos be removed from YouTube. ${ }^{250}$

The bunker scene most likely constitutes a component work having readily identified value as a standalone expressive experience. We therefore have to ask whether the addition of the subtitles is sufficient to transform the scene into something other than a copy or derivative work. ${ }^{251}$

249. Wetherbee, 22 Mich. at 320 . For a further discussion of the law, see supra note 135 and accompanying text.

250. See, e.g., Dawsonbros, Hitler Finds Out About Another Downfall Parody, FunNY OR DIE (Sept. 3, 2009), http://www.funnyordie.com/videos/0e4alfa827) hitler-finds-out-about-another-downfall-parody. For (partial) lists of such videos, see Top 10 Hitler Downfall Parodies of All Time, RANKER, http://www.ranker.com/ list/top-10-hitler-downfall-parodies-of-all-time/the-master (last modified Apr. 23, 2010) and Hitler Downfall Parodies: 25 Worth Watching, The TELEGRAPH (Oct. 6, 2009, 7:00 AM), http://www.telegraph.co.uk/technology/news/6262709/HitlerDownfall-parodies-25-worth-watching.html.

251. Note that this does not raise the same issue as the music video mashup, in which I concluded that the original sound recording had not been transformed 
The argument that these mashups do not infringe would start by observing that the subtitles have been integrated seamlessly into the audiovisual work in such a way that they cannot be disaggregated by the viewer from the rest of the input. While this might also be said of certain "annotations" and "elaborations" that characterize a derivative work, the subtitles here radically alter the nature of the expressive experience, changing its effect from that of a tense dramatic historical recreation into a humorous farce. It is true that someone who spoke German but not English might be able to ignore the subtitles and focus on the original scene, but their presence would be an annoying distraction that would detract from the utility of this version for making beneficial use of the original work, much as a thumbnail image conveying a search result is a suboptimal means of deriving aesthetic benefit from the original image. ${ }^{252}$ Whereas for an English speaker, the subtitles effect a determinative alteration of the expressive experience of watching the clip.

On the other hand, once we accept the premise that the underlying film scene is a work of authorship in its own right, the use of both audio and visual elements in their entirety, ${ }^{253}$ and in such a way that they constitute nearly the entirety of the material appearing in the mashup, should give us pause. Certainly if we use the relative value approach, we will be hard-pressed to assert that the value of the original scene is "swallowed up and rendered insignificant" in the mashup. ${ }^{254}$ Indeed, one can argue that the humor of the mashup depends crucially on one's simultaneously experiencing the scene as it was originally intended, and juxtaposing that drama with the absurd content in the subtitles. If the scene were not as well-produced and acted as it is, if its depiction of the last Hitlerian tirade had less verisimilitude, the joke would not be nearly as funny. This, then, is an example of a hard case that remains a hard case under my proposed analysis.

\section{Conclusion}

It would be impossible in one article to completely work out the implications of an in rem approach to copyright law, or to mount an argument that on balance such an approach is better than any alternative. I cannot even say that everyone who wants to reinvigorate the in rem under-

by being used as a soundtrack. Here, though the only alterations are visual, there is no independent original sound recording to infringe, because the soundtrack to the Hitler scene was originally created to serve as "the sounds accompanying a motion picture or other audiovisual work," and is therefore excluded from the statutory definition of "sound recording." 17 U.S.C. $\$ 101$ (2006).

252. For further discussion, see supra note 214 and accompanying text.

253. One can contrast this with Woody Allen's WHAT's UP, TIGER LILY? in which the original soundtrack of a Japanese spy thriller was completely removed and replaced with a comedic one. What's UP, Tiger LiLy? (Benedict Pictures Corp. et al. 1966)

254. For a further discussion, see supra note 249 and accompanying text. 
standing of property rights would agree with the manner in which I have attempted here to apply it to copyright. I believe I have, however, shown at least the following things.

A propertarian approach to copyright need not be essentialist or expansionist. Property is an attempt to coordinate the potentially conflicting uses of resources by means of recognizing in rem rights to objects of ownership. An important part of the propertarian strategy is to recognize owners' presumptive right to exclude certain (designedly overinclusive) categories of action affecting their property. Equally important, however, are the tasks of providing well-defined boundaries to the object of ownership, and calibrating the right to exclude so as not unjustifiably to burden duty-holders' freedom to make beneficial use of their own property. The in rem approach seeks as far as possible to make these judgments about justifiable versus unjustifiable burdens on a categorical rather than ad hoc basis, and to use criteria that are socially intelligible without reference to the subjective preferences of individual owners or users. If carried out successfully, this strategy promises to result in benefits from increased certainty of rights and duties that outweigh the costs of occasional exclusion by rights holders of non-conflicting uses.

I have attempted to provide a sketch of one way in which copyright doctrine might be made to comply with these principles better than it currently does. This sketch centers on the application of a much more stringent understanding of substantial similarity than is often applied at present, one that focuses on works of authorship rather than protected expression and, in consequence, requires robust showings of comprehensive similarity to find that a work has been infringed. I cannot claim that the approach I propose would lead to perfectly clear answers in every case (an impossible criterion in any event). I do claim that it would result in at least marginally clearer answers across a wide range of cases, in important part because many issues that now require resort to fair use doctrine would be decided as a matter of (relatively) straightforward application of intrinsic limits on the scope of the owner's rights. This leads to my second important point.

A propertarian approach to copyright is fully compatible with the goal of protecting free speech. In this article, I have tried to show that many of the instances in which current copyright doctrine suppresses free speech result from a failure to focus on the identity of the owned work. The refocusing of copyright doctrine proposed here would eliminate a large portion of the suppressed speech causes célèbres that animate Netanel's book and other attacks on either propertarian copyright or copyright in general. What I have provided here does not by any means purport to solve all the problems with copyright that Netanel identifies. But nor does it exhaust the ways in which propertarian reasoning may actually suggest reforms that address some of these concerns. I have written elsewhere (in a patent context) about the circumstances under which property doctrine and the- 
ory may counsel withholding of injunctive relief even for actual conflicting use. ${ }^{255}$ Propertarian reasoning may also come down on the side of reinvigorated formal requirements (think of land title registry) that could ameliorate the problems of clearance costs and orphaned works. ${ }^{256}$ Once one understands that property is not a one-size-fits-all set of rules for every situation, but a principled approach to solving coordination problems and protecting people's ability to plan and benefit from productive effort, it also becomes evident that the reasons justifying perpetual ownership of land do not apply to the interests protected by copyright. ${ }^{257}$

I do not wish to suggest that a propertarian approach to copyright (or any other, for that matter) will ever generate all the specific results that Netanel or others-or I, myself-would like to see. Much of the impulse to resist codifying fair use in any clear categorical way (as I have suggested here should be done for "privileged uses"), and instead to keep it as an ex post, ad hoc balancing test, stems from the desire to make sure that we always have wiggle room to find an exemption for particular users or uses we happen to favor. But this flexibility has costs, too, and property law embodies a long history of efforts to find the right balance between rules and standards and to assign each its proper sphere. The problems addressed by ownership of tangible things are not identical in all respects to those that underlie ownership of intellectual works, and careless propertybased rhetoric can lead to error. But the areas of commonality are great, and we should not be too quick to conclude that property is always the problem and never the solution.

255. See generally Newman, supra note 43.

256. See Dagan, supra note 27 , at 92 (suggesting that reinvigoration of copyright formalities would be supported by property law and theory).

257. See Epstein, supra note 35, at 821-26. 
